\title{
Immunohistochemical expression of insulin-like growth factor-1Ec in primary endometrial carcinoma: Association with PTEN, p53 and survivin expression
}

\author{
AGGELIS STAVROPOULOS ${ }^{1}$, MICHAIL VARRAS $^{2}$, ANASTASSIOS PHILIPPOU $^{3}$, THIVI VASILAKAKI ${ }^{4}$, \\ VIKTORIA-KONSTANTINA VARRA ${ }^{5}$, FANI-NIKI VARRA ${ }^{6}$, AIKATERINI TSAVARI $^{4}$, \\ ANDREAS C. LAZARIS $^{7}$ and MICHAEL KOUTSILIERIS ${ }^{3}$
}

\begin{abstract}
${ }^{1}$ Fourth Obstetrics and Gynecology Department; ${ }^{2}$ Fifth Obstetrics and Gynecology Department,
'Elena Venizelou' General Hospital, Athens $11521 ;{ }^{3}$ Department of Physiology, Medical School,

National Kapodistrian University, Athens 11527; ${ }^{4}$ Pathology Department, 'Tzaneio' General Hospital, Piraeus 18536;

${ }^{5}$ Pharmacy Department, University of Patras, Patra 26504, Greece; ${ }^{6}$ Pharmacy Department, Frederick University, Nicosia 1036, Cyprus; ${ }^{7}$ First Pathology Department, Medical School, National Kapodistrian University, Athens 11527, Greece
\end{abstract}

Received April 3, 2020; Accepted September 16, 2020

DOI: $10.3892 / 01.2020 .12258$

\begin{abstract}
Chronic hyperinsulinemia due to insulin resistance and elevated levels of insulin-like growth factor (IGF)-1 and IGF-2 are suggestive of a significantly higher risk of endometrial carcinoma. There is a wealth of evidence showing differential expression of IGF-1 isoforms in various types of cancer. In the present study, 99 archived endometrial carcinoma tissue sections were retrospectively assessed by immunohistochemistry for IGF-1Ec isoform expression. Expression of IGF-1Ec was also assessed in nine cases of non-neoplastic endometrial tissue adjacent to the tumor, in 30 cases with normal endometrium and in 30 cases with endometrial hyperplasia. Furthermore, the association between IGF-1Ec and the concurrent expression of phosphatase and tensin homologue deleted on chromosome 10 (PTEN), p53 or survivin was assessed, as well as their combined expression in association with clinicopathological variables. In endometrial carcinoma, IGF-1Ec expression was high in non-endometrioid carcinoma (serous papillary or clear cell carcinoma) compared with that in endometrioid adenocarcinoma. IGF-1Ec expression was also high in the presence of tumoral necrosis. Furthermore, there was a significant correlation between the histological differentiation and the sum of staining intensity and the number of IGF-1Ec immunopositive cells in
\end{abstract}

Correspondence to: Dr Michail Varras, Fifth Obstetrics and Gynecology Department, 'Elena Venizelou' General Hospital, Plateia Elenas Venizelou 2, Ampelokipoi, Athens 11521, Greece E-mail: mnvarras@otenet.gr

Key words: endometrial carcinoma, carcinogenesis, insulin-like growth factor-1, insulin-like growth factor-1Ec isoform, p53, phosphatase and tensin homologue deleted on chromosome 10 , survivin, concomitant, expression endometrial carcinoma. There was a moderate negative correlation between co-expression of IGF-1Ec and PTEN, for both the number of immunopositive cells $(\mathrm{P}=0.006, \rho=-0.343)$ and the sum of staining (scores and intensity; $\mathrm{P}=0.006, \rho=-0.343$ ). Furthermore, there was a positive correlation between the sum of staining (scores and intensity) and co-expression of IGF-1Ec and survivin ( $\mathrm{P}=0.043, \rho=0.225)$. However, there was no association between concomitant expression of IGF-1Ec and p53. These results emphasized the importance of IGF-1Ec expression during development of non-estrogen dependent endometrial adenocarcinoma. IGF-1Ec and PTEN may function opposingly during endometrial carcinogenesis. By contrast, IGF-1Ec and survivin may share common molecular pathways and may promote, in parallel, tumoral development.

\section{Introduction}

Endometrial carcinoma accounts for $4.8 \%$ of all cancer cases in women, and the life-time risk of development is $2-3 \%$. Endometrial carcinoma is the most common type of malignancy of the female genital tract and the fourth most common type of cancer in females after breast, colorectal and lung cancer. Endometrial carcinoma can be either hereditary or sporadic in 10 and $90 \%$ of women, respectively (1-8). Endometrial carcinoma is classified as type I or type II based on the pathological histology and clinical profile. Type I endometrial carcinoma usually occurs in pre- and peri-menopausal women, accounts for $80-90 \%$ of endometrial cancer cases, and consists of endometrioid or mucinous adenocarcinomas. Type I endometrial carcinoma is an estrogen-dependent neoplasm of a low histological grade and arises through persistent, unopposed estrogen stimulation of the endometrium with a strong link to obesity. Typically, type I endometrial carcinoma neoplasms begin as endometrial hyperplasia and in particular, complex endometrial hyperplasia with atypia. The early diagnosis and treatment of endometrial carcinoma type I has favorable prognosis with a 5-year overall survival rate 
of $85-90 \%(1,5,9-11)$. Type II endometrial adenocarcinoma accounts for $10-20 \%$ of endometrial cancer cases and consists of high grade serous papillary and clear cell adenocarcinoma. They are estrogen-independent neoplasms and frequently begin as endometrial atrophy. Endometrial carcinoma type II neoplasms are aggressive with exhibit metastasis at an early stage, and patients have a poor prognosis and a 5-year survival rate between $30-70 \%(9,12)$.

The insulin-like growth factor (IGF) system includes: i) IGF-1, which is a growth hormone-dependent growth factor with a molecular weight of $7,650 \mathrm{kDa}$, also known as somatomedin C; ii) IGF-2, which is a small peptide that shares $\sim 60 \%$ of amino acid homology with IGF-1 and $40 \%$ with pro-insulin; iii) type 1 IGF receptor (IGF-1R), which is a tyrosine kinase receptor with $>50 \%$ of homology with the insulin receptor (IR) and binds to IGF-1 with the highest affinity or to IGF-2 with low affinity, and mediates the majority of the somatomedin-like actions of IGF-1 and IGF-2; iv) type 2 IGF receptor (IGF-2R), which is a transmembrane single-chain glycoprotein known as cation-independent mannose-6-phosphate receptor and binds to IGF-1 with very low affinity and to IGF-2 but not to insulin; v) IR, which is a cell surface tyrosine kinase receptor that activates the ras-raf-MAPK-ERK, PI3K-AKT and mTOR signaling pathways, and binds primarily to insulin, and to a lesser degree with IGF-1 and IGF-2; vi) IR isoform A (IR-A), which is derived from alternative splicing of IR mRNA with the absence of exon 11, and exhibits a high affinity for insulin; vii) IR isoform $B$ (IR-B), which is derived from alternative splicing of IR mRNA with inclusion of exon 11, and has a lower binding affinity for insulin than IR-A; viii) the IR/IGR-1R hybrid, which is hypothesized to function predominantly as an IGF-1R; and ix) at least six insulin-like growth factor binding proteins (IGFBPs) IGFBP-1-6, which bind to IGF-1 and IGF-2 with high affinity (13-26). The availability and biological activities of IGFs are controlled and modulated by IGFBPs $(27,28)$. For example, IGFBP-3 binds to IGF-1 forming a $150 \mathrm{kDa}$ ternary complex, which protects IGF-1 from proteolytic degradation. Pericellular proteases found in biological fluids, cleave IGFBP-3, releasing free IGF-1 at the cell surface, which diffuses into tissues and binds to IGF-1R to exert its biological functions $(20,21,29-36)$. IGFBPs compete with IGF-1R and have higher binding affinity to IGF-1 compared with IGF-1R. Binding of IGF-1 to IGFBPs suppresses IGF-1 actions $(35,37,38)$. Additionally, there is a group of cysteine-rich proteins, known as IGFBP-related proteins that shares important structural similarities with IGFBPs, but this group of proteins exhibits a low binding affinity for IGF (30).

In humans, the IGF-1 gene is present in the human genome as a single copy with 6 exons and 5 introns. The transcription of the IGF-1 gene is controlled by two promoters (P1 and $\mathrm{P} 2$ ), which are located before exons 1 and 2 respectively (39-43). It is hypothesized that the $\mathrm{P} 2$ promoter encodes the endocrine IGF-1 form, which remains under the control of growth hormone (42). Alternative splicing of the exons of the IGF-1 genes produces multiple heterogeneous IGF-1 mRNA transcripts, including isoforms of mRNA called IGF-1Ea, IGF-1Eb and IGF-1Ec (42,44-48). The translation of these mRNA isoforms produces various isoforms of precursor IGF-1 proteins (45). IGF-1 activity is mediated by mature IGF-1, but IGF-1 is synthesized as a precursor protein (49). The precursor protein is termed prepro-IGF-1, which contains a signal peptide and pro-IGF-1 (50). The signal peptide is removed in the endoplasmic reticulum (50). Specific enzymes cleave post-translationally the polypeptidic pro-IGF-1 into mature IGF-1, and free the carboxyl-terminal extension E-peptide (30,51-54). The E-peptide possesses distinct bioactivity compared with the mature form of IGF-1 $(30,55,56)$. Exon 3 encodes parts of the signal peptide and the mature peptide, which is common to all IGF-1 isoforms (47). Exon 4 encodes the rest of the mature peptide and the proximal part of the E-domain (47). Therefore, the mature IGF-1 molecule is encoded exclusively by exons 3 and 4 and is composed of 70 amino acids (47). The mature IGF peptide is the biologically active peptide, and is responsible for binding to the receptors (30). Peptide Ec is encoded by exon 4, and parts of exons 5 and 6 in the IGF-1Ec isoform and is composed of the last 40 amino acids at the COO-terminal of the IGF-1Ec isoform (45-47,57-60). Fig. 1 shows the molecular structure of the human igf-1 gene, the various IGF-1 mRNA isoforms and their IGF-1 protein isoforms (IGF-1Ea, IGF-1Eb and IGF-1Ec). IGF-1Eb and IGF-1Ec are produced in negligible amounts, and the predominantly expressed isoform under physiological conditions is IGF-1Ea (60). IGF-1 synthesis in several tissues exerts autocrine and paracrine effects. IGF-1 production in the liver exhibits endocrine activity primarily $(13,19,21,39,47,61,62)$. Various studies have demonstrated the presence of IGF-1 in the endometrium during a normal menstrual cycle (63). Estrogen increases the expression of IGF-1 in the uterus and IGF-1 is required to mediate its mitogenic effect on the endometrium via IGF-1R, and possibly via hybrid IR/IGF-1R (20,27,34,64-66). Progesterone has been reported to increase IGF synthesis to antagonize estrogen-induced cell proliferation $(27,28)$.

There is epidemiological evidence suggestive of a significantly higher risk of endometrial carcinoma in women with chronic hyperinsulinemia from insulin resistance (67). In addition, IGF-1 and IGF-2 have been reported to be involved in endometrial carcinogenesis (68). However, the results of various studies which evaluated the biological significance of IGF-1 and IGF-2 in endometrial carcinoma have produced conflicting results, and are the subject of debate (22). The biological and clinical role of IGF-1Ec isoform expression in endometrial carcinogenesis has not been studied so far, to the best of our knowledge. The aim of the present study was to investigate the expression of IGF-1Ec isoform immunohistochemically in endometrial carcinoma in Greek patients, in order to determine its potential role in endometrial carcinogenesis, and whether it is associated with well-established clinicopathological parameters.

\section{Material and methods}

Patients. A total of 99 patients with primary endometrial carcinoma who underwent surgical treatment with total abdominal hysterectomy and bilateral salpingo-oophorectomy were selected randomly and studied retrospectively using archived formalin-fixed paraffin-embedded specimens. The control group with normal endometrium consisted of 30 cases (including 12 proliferative and 8 secretory cases of endometrium, and 10 cases of atrophic endometrium); the group with hyperplastic endometrium consisted of 30 cases (including 28 simple, 1 complex and 1 complex with atypia 

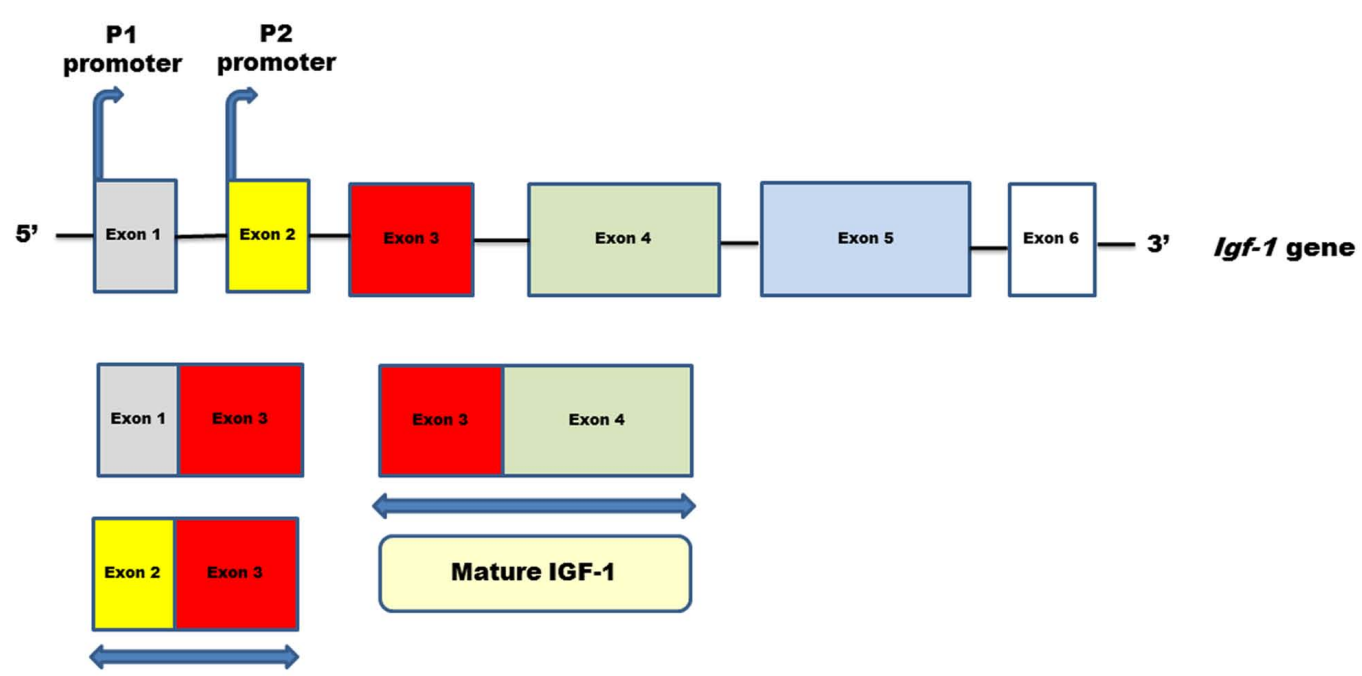

Mature IGF-1
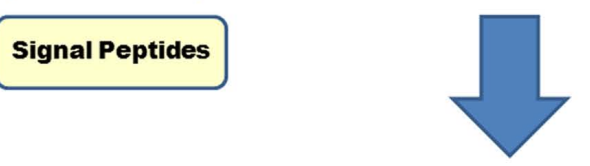

IGF-1 mRNA transcripts

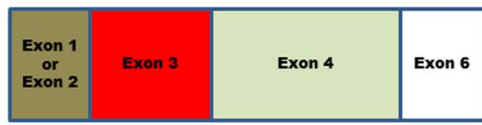

IGF-1Ea
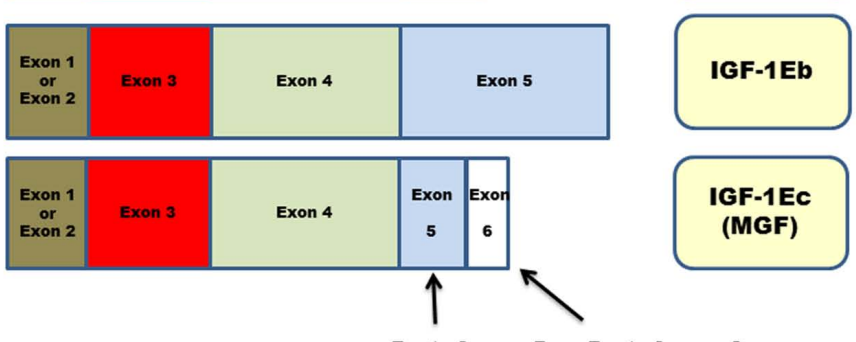

Part of exon $5 \quad$ Part of exon 6

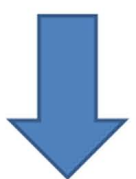

IGF-1 protein isoforms

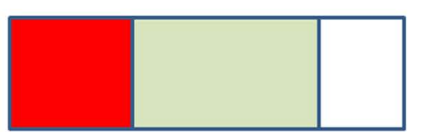

IGF-1Ea Peptide

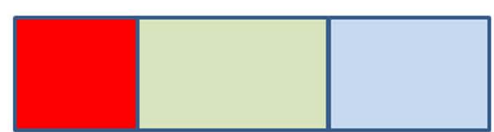

IGF-1Eb Peptide

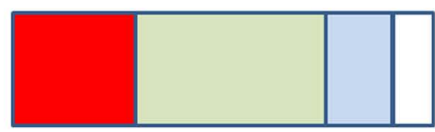

IGF-1Ec Peptide

Figure 1. Molecular structure of the human igf-1 gene. The human igf- 1 gene is composed of six exons and five introns. Transcription is controlled by one of the two promoters (P1 and P2) located in exon 1 and 2, respectively. The P2 promoter encodes the endocrine IGF-1 form, which remains under the control of growth hormone (GH). Various IGF-1 mRNA isoforms are generated by alternative splicing. Exons 1 and 2 are alternatively utilized and comprise class I and II, respectively. Exons 3 and 4 are common part of all known isoforms. The IGF-1Ea isoform is encoded by exons 3, 4 and 6; exon 5 is absent in isoform IGF-1Ea. The IGF-1Eb isoform is encoded by exons 3,4 and 5 . The IGF-1Ec isoform is encoded by exons 3,4 and parts of exons 5 and 6 . The translation of these mRNA isoforms produces the corresponding IGF-1 protein isoforms, i.e. the IGF-1Ea, IGF-1Eb and IGF-1c pro-peptides. The mature peptide of IGF-1 is encoded exclusively by exons 3 and 4 , is the common part of each IGF-1 isoform, responsible for binding to the receptors, and is composed of 70 amino acids. IGF, insulin-like growth factor.

endometrial hyperplasia). In addition, non-neoplastic endometrial tissue adjacent to endometrial tumor was studied in 9 cases. Endometrial biopsies without hysterectomy specimens were excluded. All patients included in the present study had not received radiation therapy, hormonal therapy or neoadjuvant chemotherapy prior to the surgery. Additionally, the patients with normal or hyperplastic endometrium did not have concomitant ovarian lesions. In the patients with endometrial carcinoma, the following histopathological parameters were determined: Histological tumor type, histological grade, depth of myometrial invasion, presence of lymph-vascular space invasion, presence of fallopian tube or ovarian invasion and presence of tumoral necrosis. Pelvic and para-aortic lymph nodes were not dissected in all of patients. Endometrial carcinomas were graded according to the World Health Organization (WHO) system. Clinical 
staging for all of the patients was performed using CT scans and MRI. Pathological confirmation of extension to the cervix was also taken into consideration for the staging of the disease. Additional details regarding the patients with endometrial carcinoma used in the present study have been described previously (69). Patients with metastases in the pelvic or para-aortic or inguinal lymph nodes were excluded from the study (FIGO stages IIIc and IVb) (69). The present study was approved by the Ethics Committee of the Medical School of the Kapodistrian University of Athens. All patients provided written informed consent before the study.

Histological analysis and evaluation of immunohistochemistry. For histological examination, endometrial carcinomas were orientated longitudinally, routinely fixed with formalin (4\% final concentration) and embedded in paraffin for subsequent immunohistochemical analysis. For histological analysis routine staining with hematoxylin and eosin was used, and a pathologist confirmed the pathological diagnosis and identified areas of tumor mass. The phosphatase and tensin homologue deleted on chromosome 10 (PTEN), p53 and survivin immunohistochemical staining was performed and evaluated as described previously $(69,70)$. Immunohistochemical staining for IGF-1Ec was performed as follows: $4-\mu \mathrm{m}$-thick microtome sections were prepared from the paraffin-fixed samples, making sure to include a sufficient quantity of neoplasm mass, which was mounted on a silane-coated glass slides, dried at $37^{\circ} \mathrm{C}$ overnight, dewaxed in xylene and rehydrated in serial dilutions of ethanol. Endogenous peroxidase activity was quenched with $1 \%$ hydrogen peroxide in distilled water for $15 \mathrm{~min}$. After two serial washes with distilled water and PBS buffer, the sections were incubated with polyclonal anti-IGF-IEc antiserum (1:1,000 in PBS) overnight at $4^{\circ} \mathrm{C}$. After washing with PBS, secondary biotinylated goat anti-rabbit IgG (Dako Real EnVision) was added for $25 \mathrm{~min}$ at room temperature, followed again by repeated PBS washes. The immunocomplex was visualized by incubating the sections in a solution of 3,3-diaminobenzidine (Dako Real EnVision) in PBS for $10 \mathrm{~min}$. Sections were stained in hematoxylin for 5 min, washed in distilled water, dehydrated in serial dilutions of ethanol and xylene and finally mounted in dibutyl phthalate xylene. Tissue sections were visualized under a light microscope. The immunohistochemical staining was followed by a series of positive and negative control reactions. Positive control sections for specificity included staining of positive controls of prostate carcinoma that are known to be IGF-1Ec positive. Negative controls were processed without adding the primary antibody in the experiment.

All slides were scored by an independent pathologist who was blinded to the characteristics of the tumors, in 10 randomly selected fields of view, at a magnification of x400 and the results are expressed as a percentage of positive staining. The neoplastic, hyperplastic and normal endometrium were evaluated separately. The scores of immunohistochemical expression of IGF-1Ec isoform, PTEN, p53 and survivin were classified into the following four categories: $0,=<5 \%$ immunopositive cells; $1,=5-25 \%$ immunopositive cells; $2,=25-75 \%$ immunopositive cells; $3,=>75 \%$ immunopositive cells. Staining intensity was defined as follows: 0 , negative; 1 , weakly positive; 2 , moderately positive; and 3 , strongly positive. The sum of the stain intensity and positive cell scores was used as the result for each section, as scored as: $0,-; 1$ and 2, +; 3 and 4, ++ ; and 5 and $6,+++$.

Statistical analysis. Categorical variables are presented as absolute (n) and relative (\%) frequencies, whereas continuous variables are presented as the median range. Associations between categorical variables were assessed using an exact Pearson's $\chi^{2}$ test. For continuous variables, differences in medians between two groups were assessed using a Mann-Whitney U test, and differences between three groups were assessed using a Kruskal-Wallis test with Dunn test for post hoc analysis. Correlations between continuous variables were assessed by Spearman's rho $(\rho)$. Multivariate linear regression models were fitted to assess the effects of covariates on the intensity of survivin staining, whilst adjusting for potential confounding variables. $\mathrm{P}<0.05$ was considered to indicate a statistically significant difference. Data were analyzed using SPSS version 23.0 (IBM Corp.).

\section{Results}

Patient characteristics. The median age of the 99 patients with endometrial carcinoma was 64 years (range 42,90). The endometrial carcinoma group included $86.9 \%$ (86 cases) endometrioid carcinomas and $13.1 \%$ (13 cases) clear cell and papillary serous endometrial carcinomas. Using the WHO grading system, the cases were distributed as follows: Well differentiated adenocarcinomas (grade 1), 20.2\% (20 cases); moderately differentiated adenocarcinomas (grade 2), $49.5 \%$ (49 cases); and poorly differentiated adenocarcinomas (grade 3), 30.3\% (30 cases). Lymph-vascular space invasion was observed in $14.1 \%$ (14 cases), while fallopian tube and/or ovarian invasion was observed in $19 \%$ (19 cases) cases. Presence of tumoral necrosis was detected in $7.1 \%$ ( 7 cases). The demographic characteristics of the patients with endometrial carcinoma has been previously published (69).

Immunohistochemical expression of IGF-1Ec in endometrial carcinoma. The scores of IGF-1Ec immunohistochemical expression were not statistically significantly associated with the mean age of the patients $(\mathrm{P}=0.402)$, the clinical stage $(\mathrm{P}=0.223)$, the depth of myometrial invasion $(\mathrm{P}=0.287)$, lymph-vascular space invasion $(\mathrm{P}=0.121)$, and fallopian tube and/or ovarian invasion $(\mathrm{P}=0.523)$ (Table I). The findings were suggestive for the histological differentiation $(\mathrm{P}=0.056)$. There was a statistically significant correlation between histological types and the scores of immunohistochemical IGF-1Ec expression $(\mathrm{P}=0.039)$. Endometrioid carcinomas included 18 cases (20.9\%) with 5-25\% IGF-1Ec immunopositive cells, 49 cases (57.0\%) with $25-75 \%$ IGF-1Ec immunopositive cells, and 13 cases $(15.1 \%)$ with $>75 \%$ IGF-1Ec immunopositive cells. In the patients with clear cell and papillary serous endometrial carcinomas, IGF-1Ec was immunohistochemically expressed in $5-25 \%$ of cells in 7 cases $(53.8 \%)$ and in $25-75 \%$ of cells in 5 cases $(38.5 \%)$. In particular, in patients with endometrioid carcinomas, there were a larger number of cases with low IGF-1Ec expression, and a smaller number of high IGF-1Ec expression than expected. The opposite was true for the patients with clear cell and serous papillary adenocarcinomas. 
Table I. Association between clinicopathological characteristics and scores of immunohistochemical IGF-1Ec expression.

\begin{tabular}{|c|c|c|c|c|}
\hline \multirow[b]{2}{*}{ Clinicopathological parameters } & \multicolumn{3}{|c|}{ IGF-1Ec staining pattern scores (\%) } & \multirow[b]{2}{*}{ P-value } \\
\hline & $5-25 \%$ positivity & $25-75 \%$ positivity & $>75 \%$ positivity & \\
\hline Age, years & & & & 0.402 \\
\hline$<60$ & $2(8.7)$ & $15(65.2)$ & $5(21.7)$ & \\
\hline$\geq 60$ & $16(21.1)$ & $41(53.9)$ & $13(17.1)$ & \\
\hline Histological type & & & & 0.039 \\
\hline Endometrioid & $18(20.9)$ & $49(57.0)$ & $13(15.1)$ & \\
\hline Clear cell and papillary serous & $0(0.0)$ & $7(53.8)$ & $5(38.5)$ & \\
\hline Clinical stage & & & & 0.223 \\
\hline I & $12(17.6)$ & $42(61.8)$ & $10(14.7)$ & \\
\hline II & $4(26.7)$ & $6(40.0)$ & $4(26.7)$ & \\
\hline III & $0(0.0)$ & $2(40.0)$ & $2(40.0)$ & \\
\hline Histological differentiation & & & & 0.056 \\
\hline G1 & $5(25.0)$ & $9(45.0)$ & $3(15.0)$ & \\
\hline $\mathrm{G} 2$ & $12(24.5)$ & $30(61.2)$ & $6(12.2)$ & \\
\hline G3 & $1(3.3)$ & $17(56.7)$ & $9(30.0)$ & \\
\hline Myometrial invasion & & & & 0.287 \\
\hline$<1 / 2$ & $9(26.5)$ & $16(47.1)$ & $6(17.6)$ & \\
\hline$\geq 1 / 2$ & $9(13.8)$ & $40(61.5)$ & $12(18.5)$ & \\
\hline Lymph-vascular space invasion & & & & 0.121 \\
\hline Positive & $0(0.0)$ & $8(57.1)$ & $6(42.9)$ & \\
\hline Negative & $8(15.7)$ & $29(56.9)$ & $10(19.6)$ & \\
\hline Fallopian tube and/or ovarian invasion & & & & 0.523 \\
\hline Positive & $4(21.1)$ & $8(42.1)$ & $6(31.6)$ & \\
\hline Negative & $3(11.1)$ & $15(55.6)$ & $6(22.2)$ & \\
\hline Tumoral necrosis & & & & 0.004 \\
\hline Yes & $1(14.3)$ & $0(0.0)$ & $5(71.4)$ & \\
\hline No & $7(13.5)$ & $32(61.5)$ & $10(19.2)$ & \\
\hline
\end{tabular}

IGF-1Ec, insulin-like growth factor-1Ec.

In addition, there was a statistically significant association between tumoral necrosis and the immunohistochemical scores of IGF-1Ec expression $(\mathrm{P}=0.004)$. In the presence of tumoral necrosis, immunohistochemical scores for IGF-1 were: $5-25 \%$ of cells in 1 case $(14.3 \%), 25-75 \%$ of cells in 0 cases $(0.0 \%)$, and $>75 \%$ of cells in 5 cases $(71.4 \%)$. If necrosis was absent, the corresponding frequencies for the three categories of IGF-1Ec expression were 7 cases $(13.5 \%)$, 32 cases $(61.5 \%)$ and 10 cases $(19.2 \%)$ respectively. Therefore, the presence of tumoral necrosis was associated with a larger number of patients with high IGF-1Ec expression and lower number of patients with moderate IGF-1Ec expression, than expected. The opposite was true for the absence of tumoral necrosis (Table II).

According to the intensity of IGF-1Ec expression out of 99 cases, 32 cases $(32.3 \%)$ exhibited strong expression and 62 cases $(62.6 \%)$ showed moderate expression. The intensity of IGF-1Ec was not statistically significantly associated with the age of the patients $(\mathrm{P}=0.802)$, the histological type $(\mathrm{P}=0.327)$, clinical stage $(\mathrm{P}=0.546)$, histological differentiation $(\mathrm{P}=0.115)$, depth of myometrial invasion $(\mathrm{P}=1.000)$, lymph-vascular space invasion
$(\mathrm{P}=0.768)$, fallopian tube and/or ovarian invasion $(\mathrm{P}=0.125)$ and the presence of tumoral necrosis $(\mathrm{P}=0.677)$ (Table II).

Table III shows the sum of staining intensity and scores of IGF-1Ec immunopositive cells in association with the clinicopathological characteristics. There was no association between the sum of staining intensity and scores of IGF-1Ec immunopositive cells with the age of the patients $(\mathrm{P}=0.875)$, histological types $(\mathrm{P}=0.383)$, clinical stage $(\mathrm{P}=0.512)$, depth of myometrial invasion $(\mathrm{P}=0.091)$, fallopian tube and/or ovarian invasion $(\mathrm{P}=0.557)$, presence of lymph-vascular space invasion $(\mathrm{P}=0.724)$ and tumoral necrosis $(\mathrm{P}=0.108)$. However, there was a statistical significance between the sum of staining intensity and scores of IGF-1Ec immunopositive cells and the histological differentiation ( $\mathrm{P}=0.014)$. Significantly, patients at Grade 1 had a lower sum of stain intensity and scores of IGF-1Ec immunopositive cells compared to patients at Grade 3 who had a higher sum of immunopositivity.

Correlation analysis between concomitant expression of $I G F-I E c$ and PTEN. The correlation between IGF-1Ec and 
Table II. Association between clinicopathological characteristics and intensity of immunohistochemical IGF-1Ec expression.

\begin{tabular}{|c|c|c|c|}
\hline \multirow[b]{2}{*}{ Clinicopathological parameters } & \multicolumn{2}{|c|}{ IGF-1Ec staining pattern intensity (\%) } & \multirow[b]{2}{*}{ P-value } \\
\hline & Moderate & Strong & \\
\hline Age, years & & & 0.802 \\
\hline$<60$ & $16(69.6)$ & $7(30.4)$ & \\
\hline$\geq 60$ & $46(60.5)$ & $25(32.9)$ & \\
\hline Histological type & & & 0.327 \\
\hline Endometrioid & $56(65.1)$ & $26(30.2)$ & \\
\hline Clear cell and papillary serous & $6(46.2)$ & $6(46.2)$ & \\
\hline Clinical stage & & & 0.546 \\
\hline I & $41(60.3)$ & $24(35.3)$ & \\
\hline II & $11(73.3)$ & $3(20.0)$ & \\
\hline III & $2(40.0)$ & $2(40.0)$ & \\
\hline Histological differentiation & & & 0.115 \\
\hline G1 & $12(60.0)$ & $7(35.0)$ & \\
\hline $\mathrm{G} 2$ & $36(73.5)$ & $12(24.5)$ & \\
\hline G3 & $14(46.7)$ & $13(43.3)$ & \\
\hline Myometrial invasion & & & 1.000 \\
\hline$<1 / 2$ & $22(64.7)$ & $11(32.4)$ & \\
\hline$\geq 1 / 2$ & $40(61.5)$ & $21(32.3)$ & \\
\hline Lymph-vascular space invasion & & & 0.768 \\
\hline Positive & $9(64.3)$ & $5(35.7)$ & \\
\hline Negative & $29(56.9)$ & $20(39.2)$ & \\
\hline Fallopian tube and/or ovarian invasion & & & 0.125 \\
\hline Positive & $14(73.7)$ & $4(21.1)$ & \\
\hline Negative & $14(51.9)$ & $12(44.4)$ & \\
\hline Tumoral necrosis & & & 0.677 \\
\hline Yes & $3(42.9)$ & $3(42.9)$ & \\
\hline No & $31(59.56)$ & $20(38.5)$ & \\
\hline
\end{tabular}

IGF-1Ec, insulin-like growth factor-1Ec.

PTEN expression was assessed using Spearman's correlation coefficient. According to the proportion of immunopositive cells (scores), there was concomitant expression of IGF-1Ec and PTEN in $27.0 \%$ of cases (17 out of 63 ) compared with $73.0 \%$ of cases without such co-expression, and this was statistically significant $(\mathrm{P}=0.006, \mathrm{P}=-0.343)$. The correlation between scores of IGF-1Ec and PTEN immunopositive cells is shown in the scatterplot (Fig. 2A).

According to the intensity of staining there was concomitant expression of IGF-1Ec and PTEN in $28.8 \%$ of cases (19 out of 66) compared with $71.2 \%$ cases without such co-expression, but this was not significant $(\mathrm{P}=0.102, \mathrm{P}=-0.203)$. The correlation between intensity of IGF-1Ec and PTEN immunopositivity is shown in the scatterplot (Fig. 2B).

Based on the sum of staining (scores and intensity) there was concomitant expression of IGF-1Ec and PTEN in 42.9 of cases (27 out of 63) compared with $57.1 \%$ without such co-expression, and the difference was statistically significant $(\mathrm{P}=0.006, \mathrm{P}=-0.342)$. The correlation between the sum of IGF-1Ec and PTEN immunopositivity is shown in the scatterplot (Fig. 2C).
In the case of concomitant expression of IGF-1Ec and PTEN, there was no correlation between the scores of immunohistochemical expression and the age of the patients $(\mathrm{P}=0.599)$, histological type $(\mathrm{P}=1.000)$, clinical stage $(\mathrm{P}=0.294)$, histological differentiation $(\mathrm{P}=0.494)$, depth of myometrial invasion $(\mathrm{P}=0.563)$, lymph-vascular space invasion $(\mathrm{P}=1.000)$, fallopian tube and/or ovarian invasion $(\mathrm{P}=0.357)$ and the presence of tumoral necrosis $(\mathrm{P}=1.000)$ (Table IV).

With the co-expression of IGF-1Ec and PTEN there was no correlations between the intensity of immunohistochemical IGF-1Ec expression and the age of the patients $(\mathrm{P}=1.000)$, histological differentiation $(\mathrm{P}=0.351)$, depth of myometrial invasion $(\mathrm{P}=1.000)$, presence of fallopian tube and/or ovarian invasion $(\mathrm{P}=0.352)$ and the presence of tumoral necrosis $(\mathrm{P}=0.637)$ (Table $\mathrm{V})$. The findings were suggestive of an association with clinical stage $(\mathrm{P}=0.056)$. There was a significant association with the histological type $(\mathrm{P}=0.014)$. Specifically, the number of patients with endometrioid carcinomas and IGF-1Ec and PTEN concomitant moderate expression intensity was higher than expected, whereas the opposite was true for the group of patients with clear and serous papillary 
Table III. Association between clinicopathological characteristics and sum of stain intensity and scores of IGF-1Ec expression.

\begin{tabular}{|c|c|c|c|c|c|c|}
\hline \multirow[b]{2}{*}{ Characteristics } & \multirow[b]{2}{*}{ Cases, $\mathrm{n}(\%)$} & \multicolumn{4}{|c|}{ IHC results of IGF-1Ec, n (\%) } & \multirow[b]{2}{*}{ P-value } \\
\hline & & 0 & + & ++ & +++ & \\
\hline Age, years & & & & & & 0.875 \\
\hline$<60$ & $22(23.9)$ & $0(0.0)$ & $2(8.7)$ & $13(56.5)$ & $7(30.4)$ & \\
\hline$\geq 60$ & $70(76.1)$ & $0(0.0)$ & $7(9.2)$ & $36(47.4)$ & $27(35.5)$ & \\
\hline Histological type & & & & & & 0.383 \\
\hline Endometrioid & $80(87.0)$ & $0(0.0)$ & $9(10.5)$ & $43(50.0)$ & $28(32.6)$ & \\
\hline Clear cell and papillary serous & $12(13.0)$ & $0(0.0)$ & $0(0.0)$ & $6(46.2)$ & $6(46.2)$ & \\
\hline Clinical stage & & & & & & 0.512 \\
\hline I & $64(78.0)$ & $0(0.0)$ & $7(10.3)$ & $33(48.5)$ & $24(35.3)$ & \\
\hline II & $14(17.1)$ & $0(0.0)$ & $1(6.7)$ & $9(60.0)$ & $4(26.7)$ & \\
\hline III & $4(4.9)$ & $0(0.0)$ & $0(0.0)$ & $1(20.0)$ & $3(60.0)$ & \\
\hline Histological differentiation & & & & & & 0.014 \\
\hline G1 & $17(18.5)$ & $0(0.0)$ & $4(20.0)$ & $6(30.0)$ & $7(35.0)$ & \\
\hline G2 & $48(52.2)$ & $0(0.0)$ & $4(8.2)$ & $32(65.3)$ & $12(24.5)$ & \\
\hline G3 & $27(29.3)$ & $0(0.0)$ & $1(3.3)$ & $11(36.7)$ & $15(50.0)$ & \\
\hline Myometrial invasion & & & & & & 0.091 \\
\hline$<1 / 2$ & $31(33.7)$ & $0(0.0)$ & $6(17.6)$ & $14(41.2)$ & $11(32.4)$ & \\
\hline$\geq 1 / 2$ & $61(66.3)$ & $0(0.0)$ & $3(4.6)$ & $35(53.8)$ & $23(35.4)$ & \\
\hline Lymph-vascular space invasion & & & & & & 0.724 \\
\hline Positive & $47(77.0)$ & $0(0.0)$ & $3(5.9)$ & $24(47.1)$ & $20(39.2)$ & \\
\hline Negative & $14(23.0)$ & $0(0.0)$ & $0(0.0)$ & $7(50.0)$ & $7(50.0)$ & \\
\hline Fallopian tube and/or ovarian invasion & & & & & & 0.557 \\
\hline Positive & $18(42.9)$ & $0(0.0)$ & $1(5.3)$ & $11(57.9)$ & $6(31.6)$ & \\
\hline Negative & $24(57.1)$ & $0(0.0)$ & $2(7.4)$ & $10(37.0)$ & $12(44.4)$ & \\
\hline Tumoral necrosis & & & & & & 0.108 \\
\hline Yes & $6(10.9)$ & $0(0.0)$ & $3(5.8)$ & $26(50.0)$ & $20(38.5)$ & \\
\hline No & $49(89.1)$ & $0(0.0)$ & $0(0)$ & $1(14.3)$ & $5(71.4)$ & \\
\hline
\end{tabular}

$\mathrm{P}<0.05$, statistically significant results; $0.05<\mathrm{P}<0.10$, suggestive results. IGF-1Ec, insulin-like growth factor-1Ec; IHC, immunohistochemistry.

carcinomas. Additionally, a statistical significance was found for lymph-vascular space invasion $(\mathrm{P}=0.021$; Table $\mathrm{V})$. In this case, the number of patients with no lymph-vascular space invasion and concomitant IGF-1Ec and PTEN expression of moderate intensity was higher, whereas the number of patients with no lymph-vascular space invasion and both IGF-1Ec and PTEN high expression was lower. The opposite was true for the patients with presence of lymph-vascular space invasion.

With the concomitant IGF-1Ec and PTEN expression, the sum of scores and staining intensity of the IGF-1Ec immunopositive cells was not correlated with the age of the patients $(\mathrm{P}=1.000)$, histological type $(\mathrm{P}=1.000)$, clinical stage $(\mathrm{P}=0.688)$, histological differentiation $(\mathrm{P}=1.000)$ or the depth of myometrial invasion $(\mathrm{P}=1.000)$ (Table VI).

Correlation analysis between concomitant expression of $I G F-1 E c$ and p53. The correlation between IGF-1Ec and p53 expression was assessed using Spearman's correlation coefficient. Based on the proportion of immunopositive cells (scores), concomitant expression of IGF-1Ec and p53 was observed in $46.8 \%$ of cases (36 out of 77) compared with $53.2 \%$ of cases without co-expression. The difference was not significant $(\mathrm{P}=0.291, \mathrm{P}=-0.122)$. The correlation between scores of IGF-1Ec and p53 immunopositive cells is shown in the scatterplot (Fig. 3A).

According to the intensity of staining, there was concomitant expression of IGF-1Ec and p53 in $44.3 \%$ of cases (35 out of 79) compared with $55.7 \%$ without such co-expression; the difference was not significant $(\mathrm{P}=0.882, \mathrm{P}=-0.017)$. The correlation between intensity of IGF-1Ec and p53 immunopositivity is shown in the scatterplot (Fig. 3B).

According to the sum of staining (scores and intensity) there was concomitant expression of IGF-1Ec and p53 in $50.6 \%$ of cases (39 out of 77) compared with $49.4 \%$ of cases without such co-expression. The findings were not statistically significant $(\mathrm{P}=0.361, \mathrm{P}=0.105)$. The correlation between the sum of survivin and p53 immunopositivity is shown in the scatterplot (Fig. 3C).

In the case of concomitant expression of IGF-1Ec and p53 there was no significant correlation between the scores of IGF-1Ec expression and the age of the patients $(\mathrm{P}=0.490)$, 
Table IV. Co-expression of IGF-1Ec and PTEN in endometrial carcinoma according to scores of immunopositive cells in relation to clinicopathological parameters.

\begin{tabular}{|c|c|c|c|c|}
\hline Characteristics & $\begin{array}{l}\text { Patients with IGF-1Ec and } \\
\text { PTEN low scores } \\
\text { expression, n (\%) }\end{array}$ & $\begin{array}{l}\text { Patients with either } \\
\text { IGF-1Ec or PTEN } \\
\text { moderate scores } \\
\text { expression, n }(\%)\end{array}$ & $\begin{array}{l}\text { Patients with } \\
\text { IGF-1Ec and } \\
\text { PTEN high scores } \\
\text { expression, n (\%) }\end{array}$ & P-value \\
\hline Age, years & & & & 0.599 \\
\hline$<60$ & $0(0.0)$ & $19(82.6)$ & $0(0.0)$ & \\
\hline$\geq 60$ & $2(2.6)$ & $49(64.5)$ & $0(0.0)$ & \\
\hline Histological type & & & & 1.000 \\
\hline Endometrioid & $2(2.3)$ & $61(70.9)$ & $0(0.0)$ & \\
\hline Clear cell and papillary serous & $0(0.0)$ & $7(53.8)$ & $0(0.0)$ & \\
\hline Clinical stage & & & & 0.294 \\
\hline I & $1(1.5)$ & $52(76.5)$ & $0(0.0)$ & \\
\hline II & $1(6.7)$ & $6(40.0)$ & $0(0.0)$ & \\
\hline III & $0(0.0)$ & $3(60.0)$ & $0(0.0)$ & \\
\hline Histological differentiation & & & & 0.494 \\
\hline G1 & $0(0.0)$ & $14(70.0)$ & $0(0.0)$ & \\
\hline $\mathrm{G} 2$ & $2(4.1)$ & $35(71.4)$ & $0(0.0)$ & \\
\hline G3 & $0(0.0)$ & $19(63.3)$ & $0(0.0)$ & \\
\hline Myometrial invasion & & & & 0.563 \\
\hline$<1 / 2$ & $0(0.0)$ & $22(64.7)$ & $0(0.0)$ & \\
\hline$\geq 1 / 2$ & $2(3.1)$ & $46(70.8)$ & $0(0.0)$ & \\
\hline Lymph-vascular space invasion & & & & 1.000 \\
\hline Yes & $0(0.0)$ & $10(71.4)$ & $0(0.0)$ & \\
\hline No & $2(3.9)$ & $32(62.7)$ & $0(0.0)$ & \\
\hline Fallopian tube and/or ovarian invasion & & & & 0.357 \\
\hline Yes & $1(5.3)$ & $9(47.4)$ & $0(0.0)$ & \\
\hline No & $0(0.0)$ & $18(66.7)$ & $0(0.0)$ & \\
\hline Tumoral necrosis & & & & 1.000 \\
\hline Yes & $0(0.0)$ & $1(14.3)$ & $0(0.0)$ & \\
\hline No & $2(3.8)$ & $35(67.3)$ & $0(0.0)$ & \\
\hline
\end{tabular}

IGF-1Ec, insulin-like growth factor-1Ec; PTEN, phosphatase and tensin homologue deleted on chromosome 10.

histological types $(\mathrm{P}=0.654)$, clinical stage $(\mathrm{P}=0.257)$, histological differentiation $(\mathrm{P}=0.751)$, depth of myometrial invasion $(\mathrm{P}=1.000)$, presence of lymph-vascular space invasion $(\mathrm{P}=0.156)$, presence of fallopian tube and/or ovarian invasion $(\mathrm{P}=0.705)$ and tumoral necrosis $(\mathrm{P}=0.125)$ as well (Table VII).

The staining intensity was not correlated with the age of the patients $(\mathrm{P}=0.371)$, clinical stage $(\mathrm{P}=0.272)$, depth of myometrial invasion $(\mathrm{P}=0.374)$, the presence of lymph-vascular space invasion $(\mathrm{P}=0.674)$, the presence of fallopian tube and/or ovarian invasion $(\mathrm{P}=0.698)$ and the presence of tumoral necrosis $(\mathrm{P}=0.581)$ (Table VIII). However, a statistical significance was found between the IGF-1Ec staining intensity and the histological types $(\mathrm{P}=0.002)$. Specifically, in patients with endometrioid carcinomas, there were a larger number of patients with concomitant IGF-1Ec and p53 moderate intensity staining than with both IGF-1Ec and p53 high positive intensity. The opposite associations were observed in patients with clear and serous papillary carcinoma. In addition, a statistically significant correlation was found for the histological differentiation as well $(\mathrm{P}=0.007)$ (Table VIII). Specifically, in patients with Grade 2 carcinoma, a larger number of patients with concomitant IGF-1Ec and p53 moderate positive intensity staining were observed, whereas in the same group fewer patients with both IGF-1Ec and p53 high positive intensity staining were observed. The opposite association was observed in patients with Grade 3 carcinoma.

The sum of scores and staining intensity of the IGF-1Ec immunopositive cells was correlated with histological type $(\mathrm{P}=0.049)$ and histological differentiation $(\mathrm{P}=0.002)$. There was no correlation found with age $(\mathrm{P}=0.375)$, clinical stage $(\mathrm{P}=0.119)$, depth of myometrial invasion $(\mathrm{P}=0.121)$, the presence of lymph-vascular space invasion $(\mathrm{P}=0.229)$, the presence of fallopian tube and/or ovarian invasion $(\mathrm{P}=0.465)$ and the presence of tumoral necrosis $(\mathrm{P}=0.079)$ (Table IX). 
Table V. Co-expression of IGF-1Ec and PTEN in endometrial carcinoma according to stain intensity of immunopositive cells in relation to clinicopathological parameters.

\begin{tabular}{|c|c|c|c|c|}
\hline Characteristics & $\begin{array}{l}\text { Patients with IGF-1Ec and } \\
\text { PTEN weak positive } \\
\text { expression, n }(\%)\end{array}$ & $\begin{array}{l}\text { Patients with either } \\
\text { IGF-1Ec or PTEN } \\
\text { moderate positive } \\
\text { expression, } \mathrm{n}(\%)\end{array}$ & $\begin{array}{l}\text { Patients with } \\
\text { IGF-1Ec and PTEN } \\
\text { strong positive } \\
\text { expression, } \mathrm{n}(\%)\end{array}$ & P-value \\
\hline Age, years & & & & 1.000 \\
\hline$<60$ & $0(0.0)$ & $18(78.3)$ & $2(8.7)$ & \\
\hline$\geq 60$ & $1(1.3)$ & $41(53.9)$ & $5(6.6)$ & \\
\hline Histological type & & & & 0.014 \\
\hline Endometrioid & $0(0.0)$ & $53(61.6)$ & $4(4.7)$ & \\
\hline Clear cell and papillary serous & $1(7.7)$ & $6(46.2)$ & $3(23.1)$ & \\
\hline Clinical stage & & & & 0.056 \\
\hline I & $0(0.0)$ & $41(60.3)$ & $3(4.4)$ & \\
\hline II & $0(0.0)$ & $10(66.7)$ & $1(6.7)$ & \\
\hline III & $0(0.0)$ & $2(40.0)$ & $2(40.0)$ & \\
\hline Histological differentiation & & & & 0.351 \\
\hline G1 & $0(0.0)$ & $9(45.0)$ & $1(5.0)$ & \\
\hline $\mathrm{G} 2$ & $0(0.0)$ & $32(65.3)$ & $2(4.1)$ & \\
\hline G3 & $1(3.3)$ & $18(60.0)$ & $4(13.3)$ & \\
\hline Myometrial invasion & & & & 1.000 \\
\hline$<1 / 2$ & $0(0.0)$ & $19(55.9)$ & $2(5.9)$ & \\
\hline$\geq 1 / 2$ & $1(1.5)$ & $40(61.5)$ & $5(7.7)$ & \\
\hline Lymph-vascular space invasion & & & & 0.021 \\
\hline Yes & $0(0.0)$ & $7(50.0)$ & $4(28.6)$ & \\
\hline No & $1(2.0)$ & $33(64.7)$ & $2(3.9)$ & \\
\hline Fallopian tube and/or ovarian invasion & & & & 0.352 \\
\hline Yes & $1(5.3)$ & $11(57.9)$ & $3(15.8)$ & \\
\hline No & $0(0.0)$ & $18(66.7)$ & $2(7.4)$ & \\
\hline Tumoral necrosis & & & & 0.637 \\
\hline Yes & $0(0.0)$ & $5(71.4)$ & $2(28.6)$ & \\
\hline No & $1(1.9)$ & $31(59.6)$ & $4(7.7)$ & \\
\hline
\end{tabular}

$\mathrm{P}<0.05$, statistically significant results; $0.05<\mathrm{P}<0.10$, suggestive results. IGF-1Ec, insulin-like growth factor-1Ec; PTEN, phosphatase and tensin homologue deleted on chromosome 10 .

Correlation analysis between concomitant expression of $I G F-I E c$ and survivin. The correlation between IGF-1Ec and survivin expression was assessed using Spearman's correlation coefficient. According to the proportion of immunopositive cells (scores), there was concomitant expression between IGF-1Ec and survivin in $54.3 \%$ of cases (44 out of 81) compared with $45.7 \%$ of cases without such co-expression; the difference was not significant $(\mathrm{P}=0.062, \mathrm{P}=0.208)$. The correlation between scores of IGF-1Ec and survivin immunopositive cells is shown in the scatterplot (Fig. 4A).

According to the intensity of staining there was concomitant expression between IGF-1Ec and survivin in $36.6 \%$ of cases (30 out of 82) compared with $63.4 \%$ without such co-expression; the difference was not statistically significant $(\mathrm{P}=0.259, \mathrm{P}=0.126)$. The correlation between intensity of IGF-1Ec and survivin immunopositivity is shown in the scatterplot (Fig. 4B).
According to the sum of staining (scores and intensity) there was concomitant expression of IGF-1Ec and survivin in $49.4 \%$ of cases (40 out of 81 ) compared with $50.6 \%$ without such co-expression. The findings were statistically significant $(\mathrm{P}=0.043, \mathrm{P}=0.225)$. The correlation between sum of IGF-1Ec and survivin immunopositivity is shown in the scatterplot (Fig. 4C).

In the case of concomitant expression of IGF-1Ec and survivin, there was a significant correlation between the scores of immunohistochemical expression and the clinical stage $(\mathrm{P}=0.040)$, histological differentiation $(\mathrm{P}=0.024)$, lymph-vascular space invasion $(\mathrm{P}=0.034)$ and the presence of tumoral necrosis $(\mathrm{P}=0.008)$. There was no correlation found for the age of the patients $(\mathrm{P}=0.558)$, histological types $(\mathrm{P}=0.508)$, the depth of the myometrial invasion $(\mathrm{P}=0.171)$ and the presence of fallopian tube and/or ovarian invasion $(\mathrm{P}=0.341)$ (Table $\mathrm{X})$. 
Table VI. Co-expression of IGF-1Ec and PTEN in endometrial carcinoma according to sum of stain intensity and scores of immunopositive cells in relation to clinicopathological parameters.

\begin{tabular}{|c|c|c|c|c|}
\hline Characteristics & $\begin{array}{l}\text { Patients with IGF-1Ec and } \\
\text { PTEN + expression, n (\%) }\end{array}$ & $\begin{array}{l}\text { Patients with either } \\
\text { IGF-1Ec or } \\
\text { PTEN ++ } \\
\text { expression, } \mathrm{n}(\%)\end{array}$ & $\begin{array}{c}\text { Patients with } \\
\text { IGF-1Ec and PTEN } \\
+++ \text { expression, } \mathrm{n}(\%)\end{array}$ & P-value \\
\hline Age, years & & & & 1.000 \\
\hline$<60$ & $0(0.0)$ & $16(69.6)$ & $1(4.3)$ & \\
\hline$\geq 60$ & $0(0.0)$ & $46(60.5)$ & $3(3.9)$ & \\
\hline Histological type & & & & 1.000 \\
\hline Endometrioid & $0(0.0)$ & $55(64.0)$ & $4(4.7)$ & \\
\hline Clear cell and papillary serous & $0(0.0)$ & $7(53.8)$ & $0(0.0)$ & \\
\hline Clinical stage & & & & 0.688 \\
\hline $\mathrm{I}$ & $0(0.0)$ & $41(60.3)$ & $4(5.9)$ & \\
\hline II & $0(0.0)$ & $10(66.7)$ & $0(0.0)$ & \\
\hline III & $0(0.0)$ & $4(80.0)$ & $0(0.0)$ & \\
\hline Histological differentiation & & & & 1.000 \\
\hline G1 & $0(0.0)$ & $10(50.0)$ & $1(5.0)$ & \\
\hline $\mathrm{G} 2$ & $0(0.0)$ & $35(71.4)$ & $2(4.1)$ & \\
\hline G3 & $0(0.0)$ & $17(56.7)$ & $1(3.3)$ & \\
\hline Myometrial invasion & & & & 1.000 \\
\hline$<1 / 2$ & $0(0.0)$ & $18(52.9)$ & $1(2.9)$ & \\
\hline$\geq 1 / 2$ & $0(0.0)$ & $44(67.7)$ & $3(4.6)$ & \\
\hline Lymph-vascular space invasion & & & & - \\
\hline Yes & $0(0.0)$ & $11(78.6)$ & $0(0.0)$ & \\
\hline No & $0(0.0)$ & $30(58.8)$ & $0(0.0)$ & \\
\hline Fallopian tube and/or ovarian invasion & & & & - \\
\hline Yes & $0(0.0)$ & $13(68.4)$ & $0(0.0)$ & \\
\hline No & $0(0.0)$ & $17(63.0)$ & $0(0.0)$ & \\
\hline Tumoral necrosis & & & & - \\
\hline Yes & $0(0.0)$ & $5(71.4)$ & $0(0.0)$ & \\
\hline No & $0(0.0)$ & $31(59.6)$ & $0(0.0)$ & \\
\hline
\end{tabular}

No P-values are available for some comparisons, due to the sparse data. IGF-1Ec, insulin-like growth factor-1Ec; PTEN, phosphatase and tensin homologue deleted on chromosome 10.

In the case of concomitant expression of IGF-1Ec and survivin, the IGF-1Ec staining intensity was correlated with histological differentiation $(\mathrm{P}=0.030)$ (Table XI). Specifically, in Grade 2 patients, there were a larger number of patients with concomitant IGF-1Ec and survivin moderate expression than expected. Furthermore, the opposite associations were observed in Grade 3 patients. There was no correlation found for the age of the patients $(\mathrm{P}=0.155)$, histological types $(\mathrm{P}=0.084)$, clinical stage $(\mathrm{P}=1.000)$, depth of myometrial invasion $(\mathrm{P}=0.615)$, the presence of lymph-vascular space invasion $(\mathrm{P}=0.360)$, fallopian tube and/or ovarian invasion $(\mathrm{P}=0.338)$ and tumoral necrosis $(\mathrm{P}=0.119)$ (Table XI).

In the case of concomitant expression of IGF-1Ec and survivin, the sum of scores and staining intensity of the IGF-1Ec immunopositive cells was correlated with histological differentiation $(\mathrm{P}=0.008)$ and the presence of tumoral necrosis $(\mathrm{P}=0.030)$ (Table XII). In terms of histological differentiation, in Grade 2 patients a larger number of patients with concomitant IGF-1Ec and survivin sum moderate expression was observed than expected, whereas in the same group, a lower number of patients with both high sum score of IGF-1Ec and survivin expression was observed. The opposite associations were observed in Grade 3 patients. Additionally, in patients without tumoral necrosis, a larger number of patients with concomitant IGF-1Ec and survivin moderate sum expression was observed, and a lower number of patients with both high IGF-1Ec and survivin sum expression. The opposite associations were observed in patients with tumoral necrosis. There was no correlation found for the age of the patients $(\mathrm{P}=0.221)$, histological type $(\mathrm{P}=0.784)$, clinical stage $(\mathrm{P}=0.235)$, depth of myometrial invasion $(\mathrm{P}=0.421)$, presence of lymph-vascular space invasion $(\mathrm{P}=0.297)$ and presence of fallopian tube and/or ovarian invasion (0.546) (Table XII). 

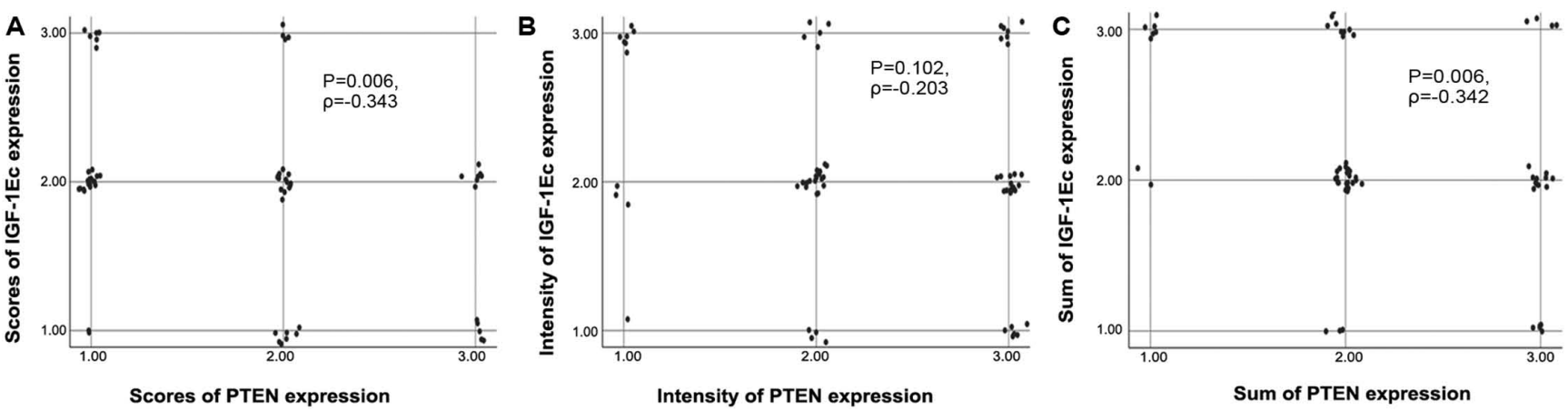

Figure 2. (A) Scatterplot of the association between positive immunostaining scores for IGF-1Ec and PTEN. There was a moderate negative correlation between IGF-1Ec and PTEN expression ( $\mathrm{P}=0.006, \rho=-0.343$ ). (B) Scatterplot of the association between staining intensity for IGF-1Ec and PTEN. There was no correlation between the staining intensity of IGF-1Ec and PTEN ( $P=0.102, \rho=-0.203)$. (C) Scatterplot of the association between the sum of staining intensity and scores of IGF-1Ec and PTEN. There was a moderate negative correlation between the sum of staining intensity and scores of IGF-1Ec and PTEN $(\mathrm{P}=0.006, \rho=-0.342)$. IGF-1Ec, insulin-like growth factor-1Ec; PTEN, phosphatase and tensin homologue deleted on chromosome 10.
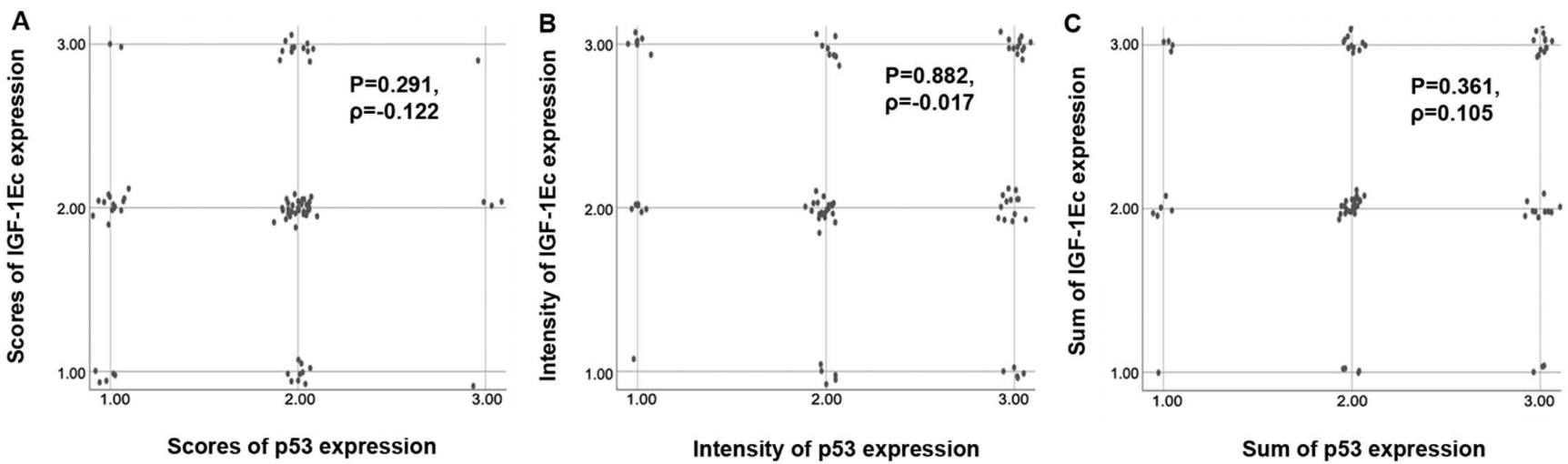

Figure 3. (A) Scatterplot of the association between positive immunostaining scores for IGF-1Ec and p53. There was no correlation between the positive immunostaining scores for IGF-1Ec and p53 ( $\mathrm{P}=0.291, \rho=-0.122)$. (B) Scatterplot of the association between staining intensity for IGF-1Ec and p53. There was no correlation between the staining intensity of IGF-1Ec and p53 ( $\mathrm{P}=0.882, \rho=-0.017)$. (C) Scatterplot of the association between the sum of staining intensity and scores of IGF-1Ec and p53. There was no correlation between the sum of staining intensity and scores of IGF-1Ec and p53 (P=0.361, $\rho=0.105$ ). IGF-1Ec, insulin-like growth factor-1Ec.

Expression of IGF-1Ec in the normal endometrium and endometrial hyperplasia, and comparison with expression in endometrial carcinoma. The expression of IGF-1Ec in endometrioid endometrial adenocarcinoma, normal endometrium and complex endometrial hyperplasia with atypia are shown in Figs. 5, 6 and 7, respectively. Fig. 8 shows the IGF-1Ec immunoexpression in simple and complex endometrial hyperplasia. In normal endometrium IGF-1Ec, staining was observed in $100 \%$ of cases and in $100 \%$ of cases of endometrial hyperplasia. There were no statistically significant differences in the IGF-1Ec expression between normal endometrium and the proliferative or secretary phase, or with atrophic endometrium based on the scores $(\mathrm{P}=0.726)$, the intensity $(\mathrm{P}=0.260)$ or the sum of immunopositivity ( $\mathrm{P}=0.706)$ (Fig. 9). However, there were differences in the levels of IGF-1Ec expression between normal endometrium, endometrial hyperplasia and endometrial carcinomas.

In particular, the intensity of IGF-1Ec immunostaining was statistically significantly different between normal and hyperplastic endometrium $(\mathrm{P}<0.001)$; in the group of patients with normal endometrium, there were more cases with moderate expression and fewer patients with high expression, while in the endometrial carcinoma group the opposite was observed (Fig. 10A). There was no statistically significant correlation between the scores or the sum of IGF-1Ec expression between normal and hyperplastic endometrium $(\mathrm{P}=0.779$ and $\mathrm{P}=0.125$ respectively).

In addition, the scores of IGF-1Ec expression was statistically significantly different between normal endometrium and endometrial carcinomas $(\mathrm{P}<0.001)$; the low or moderate scores of IGF-1Ec expression were significantly higher in patients with endometrial carcinoma compared with patients with normal endometrium (Fig. 10B). Furthermore, the sum of IGF-1Ec immunoexpression was statistically significant between normal endometrium and endometrial carcinomas $(\mathrm{P}=0.013)$; the $(+)$ or $(++)$ or $(+++)$ sum of IGF-1Ec expression were significantly higher in patients with endometrial carcinoma compared with patients with normal endometrium (Fig. 10C). However, there was no statistically significant correlation between the intensity of IGF-1Ec expression between normal and carcinomatous endometrium $(\mathrm{P}=0.142)$.

The scores of IGF-1Ec expression were statistically significantly different between endometrial hyperplasia cases and carcinomas $(\mathrm{P}<0.001)$; more patients with low or moderate IGF-1Ec expression were observed in the group with endometrial carcinomas compared with patients with 
Table VII. Co-expression of IGF-1Ec and p53 in endometrial carcinoma according to scores of immunopositive cells in relation to clinicopathological parameters.

\begin{tabular}{|c|c|c|c|c|}
\hline Characteristics & $\begin{array}{c}\text { Patients with IGF-1Ec and } \\
\text { p53 low scores } \\
\text { expression, n }(\%)\end{array}$ & $\begin{array}{l}\text { Patients with either } \\
\text { IGF-1Ec or p53 } \\
\text { moderate scores } \\
\text { expression, n }(\%)\end{array}$ & $\begin{array}{c}\text { Patients with } \\
\text { IGF-1Ec and p53 high } \\
\text { scores expression, n (\%) }\end{array}$ & P-value \\
\hline Age, years & & & & 0.490 \\
\hline$<60$ & $0(0.0)$ & $21(91.3)$ & $0(0.0)$ & \\
\hline$\geq 60$ & $5(6.6)$ & $60(78.9)$ & $1(1.3)$ & \\
\hline Histological type & & & & 0.654 \\
\hline Endometrioid & $5(5.8)$ & $68(79.1)$ & $1(1.2)$ & \\
\hline Clear cell and papillary serous & $0(0.0)$ & $13(100.0)$ & $0(0.0)$ & \\
\hline Clinical stage & & & & 0.257 \\
\hline $\mathrm{I}$ & $3(4.4)$ & $57(83.8)$ & $0(0.0)$ & \\
\hline II & $1(6.7)$ & $10(66.7)$ & $1(6.7)$ & \\
\hline III & $0(0.0)$ & $5(100.0)$ & $0(0.0)$ & \\
\hline Histological differentiation & & & & 0.751 \\
\hline $\mathrm{G} 1$ & $1(5.0)$ & $15(75.0)$ & $0(0.0)$ & \\
\hline G2 & $3(6.1)$ & $38(77.6)$ & $0(0.0)$ & \\
\hline G3 & $1(3.3)$ & $28(93.3)$ & $1(3.3)$ & \\
\hline Myometrial invasion & & & & 1.000 \\
\hline$<1 / 2$ & $2(5.9)$ & $27(79.4)$ & $0(0.0)$ & \\
\hline$\geq 1 / 2$ & $3(4.6)$ & $54(83.1)$ & $1(1.5)$ & \\
\hline Lymph-vascular space invasion & & & & 0.156 \\
\hline Yes & $0(0.0)$ & $13(92.9)$ & $1(7.1)$ & \\
\hline No & $3(5.9)$ & $38(74.5)$ & $0(0.0)$ & \\
\hline Fallopian tube and/or ovarian invasion & & & & 0.705 \\
\hline Yes & $1(5.3)$ & $14(73.7)$ & $1(5.3)$ & \\
\hline No & $1(3.7)$ & $22(81.5)$ & $0(0.0)$ & \\
\hline Tumoral necrosis & & & & 0.125 \\
\hline Yes & $0(0.0)$ & $4(57.1)$ & $1(14.3)$ & \\
\hline No & $3(5.8)$ & $41(78.8)$ & $0(0.0)$ & \\
\hline
\end{tabular}

$\mathrm{P}<0.05$, statistically significant results; $0.05<\mathrm{P}<0.10$, suggestive results. IGF-1Ec, insulin-like growth factor-1Ec.

endometrial hyperplasia (Fig. 10D). Additionally, the intensity of IGF-1Ec expression was statistically significantly different between endometrial hyperplasia cases and carcinoma cases $(\mathrm{P}<0.001)$; patients with endometrial carcinoma had higher counts of weak, moderate and strong IGF-1Ec positive expression, compared with patients with hyperplastic endometrium (Fig. 10E). The sum of IGF-1Ec expression was statistically significantly different between endometrial hyperplasia and carcinoma $(\mathrm{P}<0.001)$; the $(+)$ or $(++)$ or $(+++)$ sum of IGF-1Ec expression was significantly higher in patients with endometrial carcinoma compared with patients with hyperplastic endometrium (Fig. 10F).

In the case of concomitant IGF-1Ec and p53 expression, there were no statistically significant differences between normal and hyperplastic endometrium with scores $(\mathrm{P}=1.000)$ or the sum $(\mathrm{P}=1.000)$ of immunopositivity. However, there was a statistically significant difference between the intensity of concomitant IGF-1Ec and p53 immunostaining $(\mathrm{P}=0.001)$; in the group of patients with endometrial hyperplasia, there were more patients with strong immunostaining compared with patients with normal endometrium (Fig. 11A). In the case of concomitant IGF-1Ec and p53 expression there were no statistically significant differences between normal and carcinomatous endometrium in the scores $(\mathrm{P}=1.000)$, intensity $(\mathrm{P}=0.171)$ or $\operatorname{sum}(\mathrm{P}=1.000)$ of immunopositivity. In the case of concomitant IGF-1Ec and p53 expression there were no statistically significant differences between hyperplastic and carcinomatous endometrium with the scores $(\mathrm{P}=0.673)$ or sum $(\mathrm{P}=1.000)$ of immunopositivity. However, there was a statistically significant difference in the intensity of concomitant IGF-1Ec and p53 immunostaining $(\mathrm{P}=0.013)$; more patients with moderate intensity were observed in the group of patients with endometrial carcinomas compared with patients with endometrial hyperplasia (Fig. 11B).

In the case of concomitant IGF-1Ec and PTEN expression there were no statistically significant differences between 
Table VIII. Co-expression of IGF-1Ec and p53 in endometrial carcinoma according to stain intensity of immunopositive cells in relation to clinicopathological parameters.

\begin{tabular}{|c|c|c|c|c|}
\hline Characteristics & $\begin{array}{l}\text { Patients with IGF-1Ec and } \\
\text { p53 weak positive } \\
\text { expression, n (\%) }\end{array}$ & $\begin{array}{c}\text { Patients with } \\
\text { either IGF-1Ec or } \\
\text { p53 moderate positive } \\
\text { expression, } n(\%)\end{array}$ & $\begin{array}{l}\text { Patients with } \\
\text { IGF-1Ec and p53 } \\
\text { strong positive } \\
\text { expression, } \mathrm{n}(\%)\end{array}$ & P-value \\
\hline Age, years & & & & 0.371 \\
\hline$<60$ & $0(0.0)$ & $18(78.3)$ & $1(4.3)$ & \\
\hline$\geq 60$ & $1(1.3)$ & $45(59.2)$ & $12(15.8)$ & \\
\hline Histological type & & & & 0.002 \\
\hline Endometrioid & $1(1.2)$ & $59(68.6)$ & $7(8.1)$ & \\
\hline Clear cell and papillary serous & $0(0.0)$ & $4(30.8)$ & $6(46.2)$ & \\
\hline Clinical stage & & & & 0.272 \\
\hline I & $1(1.5)$ & $44(64.7)$ & $6(8.8)$ & \\
\hline II & $0(0.0)$ & $9(60.0)$ & $3(20.0)$ & \\
\hline III & $0(0.0)$ & $2(40.0)$ & $2(40.0)$ & \\
\hline Histological differentiation & & & & 0.007 \\
\hline $\mathrm{G} 1$ & $1(5.0)$ & $11(55.0)$ & $2(10.0)$ & \\
\hline G2 & $0(0.0)$ & $37(75.5)$ & $3(6.1)$ & \\
\hline G3 & $0(0.0)$ & $15(50.0)$ & $8(26.7)$ & \\
\hline Myometrial invasion & & & & 0.374 \\
\hline$<1 / 2$ & $0(0.0)$ & $22(64.7)$ & $2(5.9)$ & \\
\hline$\geq 1 / 2$ & $1(1.5)$ & $41(63.1)$ & $11(16.9)$ & \\
\hline Lymph-vascular space invasion & & & & 0.674 \\
\hline Yes & $0(0.0)$ & $10(71.4)$ & $3(21.4)$ & \\
\hline No & $0(0.0)$ & $33(64.7 \%)$ & $6(11.8)$ & \\
\hline Fallopian tube and/or ovarian invasion & & & & 0.698 \\
\hline Yes & $0(0.0)$ & $12(63.2)$ & $4(21.1)$ & \\
\hline No & $0(0.0)$ & $18(66.7)$ & $4(14.8)$ & \\
\hline Tumoral necrosis & & & & 0.581 \\
\hline Yes & $0(0.0)$ & $4(57.1)$ & $2(28.6)$ & \\
\hline No & $0(0.0)$ & $33(63.5)$ & $7(13.5)$ & \\
\hline
\end{tabular}

$\mathrm{P}<0.05$, statistically significant results; $0.05<\mathrm{P}<0.10$, suggestive results. IGF-1Ec, insulin-like growth factor-1Ec.

normal and hyperplastic endometrium with scores $(\mathrm{P}=0.444)$ or sum $(\mathrm{P}=0.282)$ of immunopositivity. However, there was a statistically significant difference in the intensity of concomitant IGF-1Ec and PTEN immunostaining $(\mathrm{P}=0.010)$; in the group of patients with normal endometrium there were fewer patients with strong immunostaining compared with patients with endometrial hyperplasia (Fig. 12A). In the case of concomitant IGF-1Ec and PTEN expression, there were no statistically significant differences between normal and carcinomatous endometrium with scores $(\mathrm{P}=1.000)$, or intensity $(\mathrm{P}=0.446)$ and sum $(\mathrm{P}=0.282)$ of immunopositivity. In the case of concomitant IGF-1Ec and PTEN expression, there were no statistically significant differences between hyperplastic and carcinomatous endometrium with scores $(\mathrm{P}=0.108)$ or sum $(\mathrm{P}=0.330)$ of immunopositivity. However, there was a statistically significant difference in the intensity of concomitant IGF-1Ec and PTEN immunostaining ( $\mathrm{P}=0.005)$; stronger expression was observed in patients with endometrial carcinomas compared with patients with endometrial hyperplasia (Fig. 12B).

In the case of concomitant IGF-1Ec and survivin expression there were no statistically significant differences between normal and hyperplastic endometrium with scores $(\mathrm{P}=1.000)$ or sum $(\mathrm{P}=0.375)$ of immunopositivity. However, there was a statistically significant correlation in the intensity of concomitant IGF-1Ec and survivin immunostaining $(\mathrm{P}=0.005)$; stronger expression was observed in hyperplastic endometrium compared with normal endometrium (Fig. 13A). In the case of concomitant IGF-1Ec and survivin expression, there were no statistically significant differences between normal and carcinomatous endometrium with scores $(\mathrm{P}=0.163)$, intensity $(\mathrm{P}=0.069)$ or sum $(\mathrm{P}=1.000)$ of immunopositivity. In the case of concomitant IGF-1Ec and survivin expression there were statistically significant differences between hyperplastic end carcinomatous endometrium and scores $(\mathrm{P}=0.038)$ or intensity $(\mathrm{P}=0.042)$ of immunopositivity. More patients showed higher scores and 
Table IX. Co-expression of IGF-1Ec and p53 in endometrial carcinoma according to sum of stain intensity and scores of immunopositive cells in relation to clinicopathological parameters.

\begin{tabular}{|c|c|c|c|c|}
\hline Characteristics & $\begin{array}{l}\text { Patients with IGF-1Ec and } \\
\text { p53 + expression, } \mathrm{n}(\%)\end{array}$ & $\begin{array}{l}\text { Patients with either } \\
\text { IGF-1Ec or p53 ++ } \\
\text { expression, } \mathrm{n}(\%)\end{array}$ & $\begin{array}{c}\text { Patients with } \\
\text { IGF-1Ec and } \mathrm{p} 53+++ \\
\text { expression, } \mathrm{n}(\%)\end{array}$ & P-value \\
\hline Age, years & & & & 0.375 \\
\hline$<60$ & $0(0.0)$ & $19(82.6)$ & $1(4.3)$ & \\
\hline$\geq 60$ & $1(1.3)$ & $47(61.8)$ & $12(15.8)$ & \\
\hline Histological type & & & & 0.049 \\
\hline Endometrioid & $1(1.2)$ & $59(68.6)$ & $8(9.3)$ & \\
\hline Clear cell and papillary serous & $0(0.0)$ & $7(53.8)$ & $5(38.5)$ & \\
\hline Clinical stage & & & & 0.119 \\
\hline I & $1(1.5)$ & $47(69.1)$ & $5(7.4)$ & \\
\hline II & $0(0.0)$ & $9(60.0)$ & $4(26.7)$ & \\
\hline III & $0(0.0)$ & $2(40.0)$ & $2(40.0)$ & \\
\hline Histological differentiation & & & & 0.002 \\
\hline G1 & $1(5.0)$ & $10(50.0)$ & $2(10.0)$ & \\
\hline G2 & $0(0.0)$ & $38(77.6)$ & $2(4.1)$ & \\
\hline G3 & $0(0.0)$ & $18(60.0)$ & $9(30.0)$ & \\
\hline Myometrial invasion & & & & 0.121 \\
\hline$<1 / 2$ & $0(0.0)$ & $23(67.6)$ & $1(2.9)$ & \\
\hline$\geq 1 / 2$ & $1(1.5)$ & $43(66.2)$ & $12(18.5)$ & \\
\hline Lymph-vascular space invasion & & & & 0.229 \\
\hline Yes & $0(0.0)$ & $10(71.4)$ & 4 (28.6) & \\
\hline No & $0(0.0)$ & $33(64.7)$ & $5(9.8)$ & \\
\hline Fallopian tube and/or ovarian invasion & & & & 0.465 \\
\hline Yes & $0(0.0)$ & $12(63.2)$ & $5(26.3)$ & \\
\hline No & $0(0.0)$ & $18(66.7)$ & $4(14.8)$ & \\
\hline Tumoral necrosis & & & & 0.079 \\
\hline Yes & $0(0.0)$ & $3(42.9)$ & $3(42.9)$ & \\
\hline No & $0(0.0)$ & $34(65.4)$ & $6(11.5)$ & \\
\hline
\end{tabular}

$\mathrm{P}<0.05$, statistically significant results; $0.05<\mathrm{P}<0.10$, suggestive results. IGF-1Ec, insulin-like growth factor-1Ec.

stronger concomitant expression of IGF-1Ec and survivin in patients with endometrial carcinoma compared with patients with hyperplastic endometrium (Fig. 13B and C, respectively).

\section{Discussion}

For normal endometrial physiology, appropriate balances between cellular proliferation, metabolism, cell cycle arrest and apoptosis are of critical importance. The exact pathophysiology of endometrial carcinogenesis has not been accurately determined, and may vary between individuals. A wealth of evidence has shown that activation of oncogenes, inactivation or deficiency of tumor suppressor genes, or inhibition of apoptosis results in endometrial carcinogenesis and metastasis. Some of the possible causes of all these genetic alterations include gene mutations, amplifications and chromosomal translocations or rearrangements (71-74). Thus, clinicians should take into consideration multiple factors which may affect therapeutic options in patients with endometrial carcinoma, to determine the appropriate therapeutic regimen, and avoid over- or under-treatment $(75,76)$. In clinical practice, well-established clinicopathological, prognostic and neoplastic factors are used, such as the histological type, histological grade, depth of myometrial invasion, cervical involvement, lymphovascular space invasion, or presence of tumoral necrosis. However, some patients with endometrial carcinoma may benefit from screening for molecular markers, such as growth or survival factors, oncogenes and tumor suppressor genes. The purpose of the ongoing research in this field is to allow for more optimal and personalized therapeutic regimens, with the possibility gene targeting therapies, and to improve estimation of the risk of recurrence and therefore accurately predict prognosis $(75,77,78)$. Endometrial carcinoma type I is frequently associated with alterations in phosphatase and tensing homologue deleted on chromosome 10 (PTEN), $\mathrm{K}$-ras, $\beta$-catenin, phosphatidyl-inositol-3-kinase catalytic subunit (PIK3CA), MutL homolog (MLH)-1 and MLH-6, and alterations in DNA-mismatch repair genes and microsatellite 
Table X. Co-expression of IGF-1Ec and survivin in endometrial carcinoma according to scores of immunopositive cells in relation to clinicopathological parameters.

\begin{tabular}{|c|c|c|c|c|}
\hline Characteristics & $\begin{array}{l}\text { Patients with IGF-1Ec and } \\
\text { survivin low scores } \\
\text { expression, n (\%) }\end{array}$ & $\begin{array}{l}\text { Patients with either } \\
\text { IGF-1Ec or survivin } \\
\text { moderate scores } \\
\text { expression, } \mathrm{n}(\%)\end{array}$ & $\begin{array}{l}\text { Patients with } \\
\text { IGF-1Ec and } \\
\text { survivin high scores } \\
\text { expression, n (\%) }\end{array}$ & P-value \\
\hline Age, years & & & & 0.558 \\
\hline$<60$ & $1(4.3)$ & $18(78.3)$ & $0(0.0)$ & \\
\hline$\geq 60$ & $8(10.5)$ & $54(71.1)$ & $2(2.6)$ & \\
\hline Histological type & & & & 0.508 \\
\hline Endometrioid & $9(10.5)$ & $62(72.1)$ & $2(2.3)$ & \\
\hline Clear cell and papillary serous & $0(0.0)$ & $10(76.9)$ & $0(0.0)$ & \\
\hline Clinical stage & & & & 0.040 \\
\hline $\mathrm{I}$ & $6(8.8)$ & $50(73.5)$ & $0(0.0)$ & \\
\hline II & $2(13.3)$ & $11(73.3)$ & $1(6.7)$ & \\
\hline III & $0(0.0)$ & $2(40.0)$ & $1(20.0)$ & \\
\hline Histological differentiation & & & & 0.024 \\
\hline $\mathrm{G} 1$ & $4(20.0)$ & $11(55.0)$ & $0(0.0)$ & \\
\hline G2 & $5(10.2)$ & $38(77.6)$ & $0(0.0)$ & \\
\hline G3 & $0(0.0)$ & $23(76.7)$ & $2(6.7)$ & \\
\hline Myometrial invasion & & & & 0.171 \\
\hline$<1 / 2$ & $5(14.7)$ & $20(58.8)$ & $0(0.0)$ & \\
\hline$\geq 1 / 2$ & $4(6.2)$ & $52(80.0)$ & $2(3.1)$ & \\
\hline Lymph-vascular space invasion & & & & 0.034 \\
\hline Yes & $0(0.0)$ & $10(71.4)$ & $2(14.3)$ & \\
\hline No & $4(7.8)$ & $40(78.4)$ & $0(0.0)$ & \\
\hline Fallopian tube and/or ovarian invasion & & & & 0.341 \\
\hline Yes & $2(7.4)$ & $20(74.1)$ & $0(0.0)$ & \\
\hline No & $2(10.5)$ & $13(68.4)$ & $2(10.5)$ & \\
\hline Tumoral necrosis & & & & 0.008 \\
\hline Yes & $1(14.3)$ & $3(42.9)$ & $2(28.6)$ & \\
\hline No & $3(5.8)$ & $41(78.8)$ & $0(0.0)$ & \\
\hline
\end{tabular}

$\mathrm{P}<0.05$, statistically significant results; $0.05<\mathrm{P}<0.10$, suggestive results. IGF-1Ec, insulin-like growth factor-1Ec.

instability $(79,80)$. Endometrial carcinoma type II is frequently associated with alterations in $\mathrm{p} 53$, p16, human epidermal growth factor receptor type 2 (also known as proto-oncogene neu or receptor tyrosine-protein kinase, $c$-erbB-2), E-type Cyclin E1, $c-M Y C$, fibroblast growth factor receptor 3, SOX17, STK15 and E-cadherin, including loss of heterozygosity (79-84).

Metabolic syndrome is accompanying by chronic proinflammatory status and is associated with the development of cardiovascular disease and diabetic morbidity and mortality $(85,86)$. Most patients with metabolic syndrome have hyperinsulinemia caused by insulin resistance (87). Metabolic syndrome is diagnosed by abdominal obesity defined by waist circumference $(>102-\mathrm{cm}$ in men and $>88-\mathrm{cm}$ in women), dyslipidemia accompanying by elevated triglyceride levels, low high-density lipoprotein-cholesterol levels, hyperglycemia (fasting blood glucose $>110 \mathrm{mg} / \mathrm{dl}$ ) and raised blood pressure (blood pressure $>130 / 85 \mathrm{mmHg})(86,87)$. Also, metabolic syndrome is a risk for common malignancies including liver, gastric, esophageal, colorectal, bladder, breast, hepatic, pancreatic, renal, endometrial, cervical and ovarian cancer (86-89). It seems that disarrangement by the adipose tissue in the regulation of hormones and cytokines such as sex steroids, leptin, adipokines, tumor necrosis factor (TNF)- $\alpha$ and plasminogen activator inhibitor-1 leads to chronic inflammation and related carcinogenesis $(86,90,91)$. Chronic mitogenic endometrial stimulation by the elevated free estrogen levels is thought to be a risk factor for carcinogenesis through the activation of estrogen receptor- $\alpha$. In addition, estrogens can induce the secretion of vascular endothelial factor and stimulate angiogenesis $(92,93)$. Disturbances in the function of the IGF/IGF-1R/IGFBPs system may be responsible for the induction of carcinogenesis (22). In particular, in colon cancer it has been shown that IGF-1 is associated with an increase in motility and migration of malignant colonic cells through reorganization of integrin receptors, modulation of E-cadherin/catenins complex function and activation of protein kinases $C-\gamma$ and $C-\delta(94,95)$. 
Table XI. Co-expression of IGF-1Ec and survivin in endometrial carcinoma according to stain intensity of immunopositive cells in relation to clinicopathological parameters.

\begin{tabular}{|c|c|c|c|c|}
\hline Characteristics & $\begin{array}{l}\text { Patients with IGF-1Ec and } \\
\text { survivin weak positive } \\
\text { expression, } \mathrm{n}(\%)\end{array}$ & $\begin{array}{l}\text { Patients with either } \\
\text { IGF-1Ec or survivin } \\
\text { moderate positive } \\
\text { expression, n }(\%)\end{array}$ & $\begin{array}{c}\text { Patients with } \\
\text { IGF-1Ec and } \\
\text { survivin strong positive } \\
\text { expression, n }(\%)\end{array}$ & P-value \\
\hline Age, years & & & & 0.155 \\
\hline$<60$ & $1(4.3)$ & $18(78.3)$ & $1(4.3)$ & \\
\hline$\geq 60$ & $3(3.9)$ & $43(566)$ & $14(18.4)$ & \\
\hline Histological type & & & & 0.084 \\
\hline Endometrioid & $4(4.7)$ & $57(66.3)$ & $11(12.8)$ & \\
\hline Clear cell and papillary serous & $0(0.0)$ & $4(30.8)$ & $4(30.8)$ & \\
\hline Clinical stage & & & & 1.000 \\
\hline I & $2(2.9)$ & $43(63.2)$ & $10(14.7)$ & \\
\hline II & $0(0.0)$ & $9(60.0)$ & $2(13.3)$ & \\
\hline III & $0(0.0)$ & $2(40.0)$ & $1(20.0)$ & \\
\hline Histological differentiation & & & & 0.030 \\
\hline G1 & $2(10.0)$ & $11(55.0)$ & $3(15.0)$ & \\
\hline $\mathrm{G} 2$ & $2(4.1)$ & $37(75.5)$ & $4(8.2)$ & \\
\hline G3 & $0(0.0)$ & $13(43.3)$ & $8(26.7)$ & \\
\hline Myometrial invasion & & & & 0.615 \\
\hline$<1 / 2$ & $2(5.9)$ & $22(64.7)$ & $4(11.8)$ & \\
\hline$\geq 1 / 2$ & $2(3.1)$ & $39(60.0)$ & $11(16.9)$ & \\
\hline Lymph-vascular space invasion & & & & 0.360 \\
\hline Yes & $0(0.0)$ & $8(57.1)$ & $4(28.6)$ & \\
\hline No & $3(5.9)$ & $30(58.8 \%)$ & $7(13.7)$ & \\
\hline Fallopian tube and/or ovarian invasion & & & & 0.338 \\
\hline Yes & $0(0.0)$ & $12(63.2)$ & $2(10.5)$ & \\
\hline No & $3(11.1)$ & $15(55.6)$ & $5(18.5)$ & \\
\hline Tumoral necrosis & & & & 0.119 \\
\hline Yes & $0(0.0)$ & $3(42.9)$ & $3(42.9)$ & \\
\hline No & $3(5.8)$ & $31(59.6)$ & $6(11.5)$ & \\
\hline
\end{tabular}

$\mathrm{P}<0.05$, statistically significant results; $0.05<\mathrm{P}<0.10$, suggestive results. IGF-1Ec, insulin-like growth factor-1Ec.

Additionally, there may be a close association between IGF-1 and regulation of vascular endothelial growth factor (VEGF) expression in human colon cancer through induction of transcription of the VEGF gene (96). In a mouse model of colon cancer, the administration of recombinant human IGF-1 has been shown to increase tumor mass, growth of cecum tumors, and increase metastasis to the liver, supporting the hypothesis that circulating IGF-1 levels may serve an important role in tumor development and metastasis of these neoplasms (97). In addition, elevated IGF-1 levels in obesity and hyperinsulinemia promote endometrial neoplastic transformation (97). Impaired glucose management, hyperglycemia and expression of insulin receptor trigger cancer cell proliferation and inhibit cancer cell apoptosis $(92,98)$. Furthermore, there is a growing interest in the different expression patterns of IGF-1 splice transcripts in normal vs. pathological tissues in order to determine the potential role of IGF-1 isoforms and immature IGF-1 products, and in particular, the role of IGF-1Ec in the development of several pathological conditions $(47,48,60,99,100)$. The IGF-1Ec peptide is a cellular and secreted mitogen peptide, which was originally identified in the liver and serves a critical role in development and growth of the skeletal muscle (46,101-105). IGF-1Ec may serve a role in skeletal and cardiac muscle regeneration and hypertrophy after exercise-induced skeletal muscle damage or myocardial infarction (106-108). Milingos et al (20) suggested that the expression of IGF-1Ec isoform may be associated with the progression of endometriosis. In addition, it has been shown that in prostate cancer cells the exogenous administration of a synthetic 24-amino acid peptide of the COO-terminal of the IGF-1Ec isoform (parts of exons 5 and 6 of the igf- 1 gene) were associated with the proliferation of neoplasmatic cells (109). Therefore, there is strong evidence that IGF-1Ec serve a pivotal role in stimulating somatic cell proliferation and growth, in regulating differentiation and migration, and reducing apoptosis during cancer cell growth $(21,22,32,35,58,59,66,110-113)$. Furthermore, clinical studies have shown that treatment with 
Table XII. Co-expression of IGF-1Ec and survivin in endometrial carcinoma according to sum of stain intensity and scores of immunopositive cells in relation to clinicopathological parameters.

\begin{tabular}{|c|c|c|c|c|}
\hline Characteristics & $\begin{array}{l}\text { Patients with IGF-1Ec and } \\
\text { survivin + expression, n (\%) }\end{array}$ & $\begin{array}{c}\text { Patients with } \\
\text { either IGF-1Ec or } \\
\text { survivin }++ \\
\text { expression, } \mathrm{n}(\%)\end{array}$ & $\begin{array}{c}\text { Patients with } \\
\text { IGF-1Ec and } \\
\text { survivin }+++ \\
\text { expression, n }(\%)\end{array}$ & P-value \\
\hline Age, years & & & & 0.221 \\
\hline$<60$ & $1(4.3)$ & $17(73.9)$ & $1(4.3)$ & \\
\hline$\geq 60$ & $2(2.6)$ & $45(59.2)$ & $15(19.7)$ & \\
\hline Histological type & & & & 0.784 \\
\hline Endometrioid & $3(3.5)$ & $55(64.0)$ & $13(15.1)$ & \\
\hline Clear cell and papillary serous & $0(0.0)$ & $7(53.8)$ & $3(23.1)$ & \\
\hline Clinical stage & & & & 0.235 \\
\hline I & $2(2.9)$ & $44(64.7)$ & $9(13.2)$ & \\
\hline II & $0(0.0)$ & $10(66.7)$ & $3(20.0)$ & \\
\hline III & $0(0.0)$ & $1(20.0)$ & $2(40.0)$ & \\
\hline Histological differentiation & & & & 0.008 \\
\hline G1 & $2(10.0)$ & $9(45.0)$ & $3(15.0)$ & \\
\hline G2 & $1(2.0)$ & $39(79.6)$ & $4(8.2)$ & \\
\hline G3 & $0(0.0)$ & $14(46.7)$ & $9(30.0)$ & \\
\hline Myometrial invasion & & & & 0.421 \\
\hline$<1 / 2$ & $2(5.9)$ & $20(58.8)$ & $4(11.8)$ & \\
\hline$\geq 1 / 2$ & $1(1.5)$ & $42(64.6)$ & $12(18.5)$ & \\
\hline Lymph-vascular space invasion & & & & 0.297 \\
\hline Yes & $2(3.9)$ & $30(58.8)$ & $7(13.7)$ & \\
\hline No & $0(0.0)$ & $8(57.1)$ & $5(35.7)$ & \\
\hline Fallopian tube and/or ovarian invasion & & & & 0.546 \\
\hline Yes & $0(0.0)$ & $12(63.2)$ & $4(21.1)$ & \\
\hline No & $2(7.4)$ & $15(55.6)$ & $4(14.8)$ & \\
\hline Tumoral necrosis & & & & 0.030 \\
\hline Yes & $0(0.0)$ & $2(28.6)$ & $4(57.1)$ & \\
\hline No & $2(3.8)$ & $32(61.5)$ & $6(11.5)$ & \\
\hline
\end{tabular}

$\mathrm{P}<0.05$, statistically significant results; $0.05<\mathrm{P}<0.10$, suggestive results.
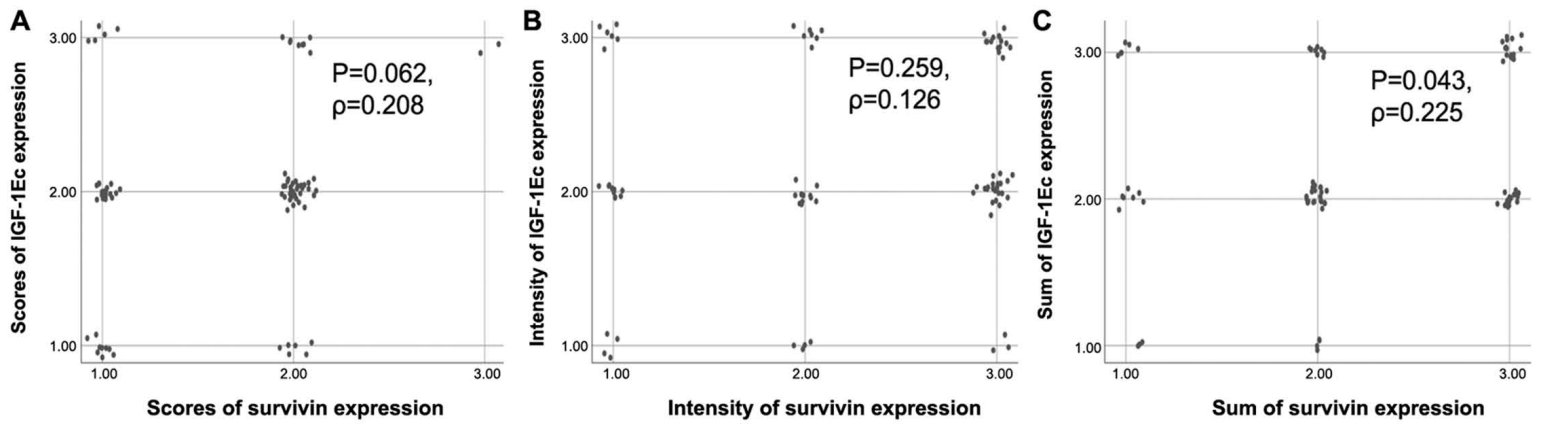

Figure 4. (A) Scatterplot of the association between positive immunostaining scores for IGF-1Ec and survivin. There was no correlation between the positive immunostaining scores for IGF-1Ec and survivin ( $\mathrm{P}=0.062, \rho=0.208)$. (B) Scatterplot of the association between staining intensity for IGF-1Ec and survivin. There was no correlation between the staining intensity of IGF-1Ec and survivin $(\mathrm{P}=0.259, \rho=0.126)$. (C) Scatterplot of the association between the sum of stain intensity and scores of IGF-1Ec and survivin. There was a positive correlation between the sum of staining intensity and scores of IGF-1Ec and survivin $(\mathrm{P}=0.043, \rho=0.225)$. IGF-1Ec, insulin-like growth factor-1Ec.

metformin exhibits antiproliferative effects and restrains endometrial cancer growth $(114,115)$.
In the present study, the expression of IGF-1Ec in endometrial adenocarcinoma tissues was compared with adjacent 

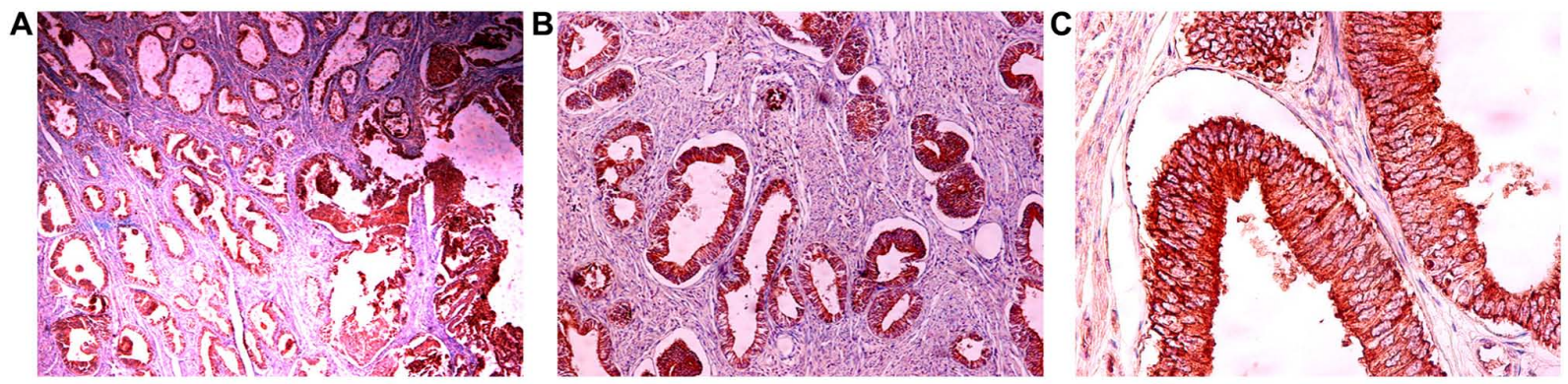

Figure 5. Immunohistochemical expression of IGF-1Ec in endometrioid endometrial adenocarcinomas. IGF-1Ec immunohistochemical staining of tissues at a magnification of (A) x40; (B) x100; and (C) x400. IGF-1Ec, insulin-like growth factor-1Ec.
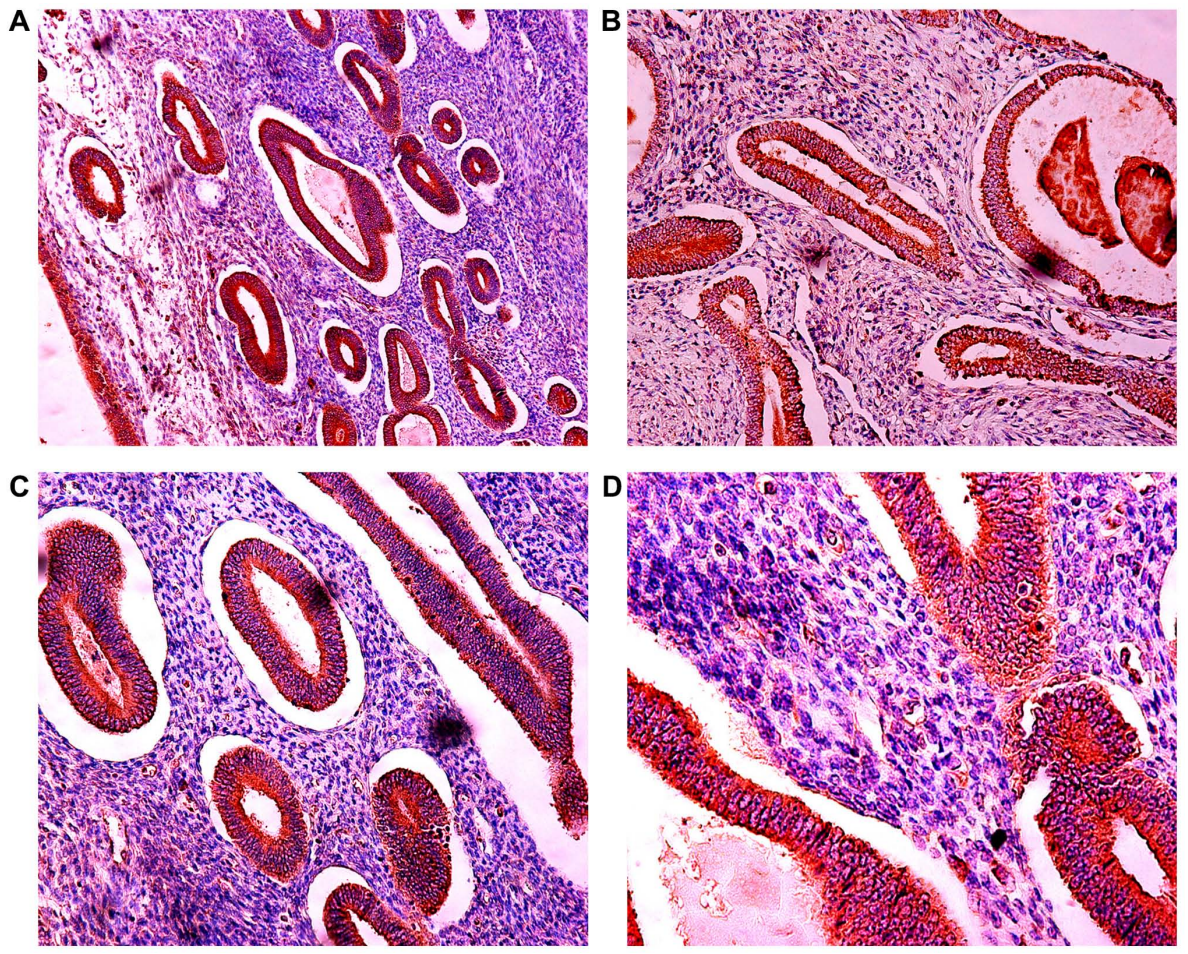

Figure 6. Immunohistochemical expression of IGF-1Ec in normal endometrium. IGF-1Ec immunohistochemical staining of tissues at a magnification of (A) $\mathrm{x} 100$; (B and C) x200; and (D) x400.

histologically normal tissues, endometrial hyperplasia and normal endometrial tissues. Positive staining for IGF-1Ec was observed in the primary endometrial tumors and hyperplastic endometrium, the first study to show this, to the best of our knowledge. The intensity or sum of IGF-1Ec expression in normal, hyperplastic and malignant endometrium were also shown to differ. The continuous expression of IGF-1Ec supports an autocrine and/or paracrine role in the endometrial pathophysiology. This, it is hypothesized that the different levels of expression of IGF-1Ec may be a critical mediator of transformation from normal endometrium to hyperplastic and then to cancerous. The upregulated expression of IGF-1Ec in premalignant biopsy samples may be a marker of progression to malignancy. Thus, IGF-1Ec upregulation may initiate malignant endometrial transformation, highlighting the importance of IGF-1Ec in progression of endometrial carcinoma. Continuous stimulation of IGF-1Ec with a possible synergistic action with growth or survival factors, oncogenes, tumor suppressor genes or hormones may result in uncontrolled cell proliferation resulting in malignant endometrial transformation. This hypothesis is supported by the results of the present study, which showed significantly stronger co-expression of IGF-1Ec with p53, PTEN or survivin in hyperplastic vs. normal or cancerous vs. hyperplastic endometrium. Interestingly, there was no statistically significant difference between normal-adjacent and cancerous endometrium, suggesting that in the histologically normal adjacent endometrium, the necessary molecular alterations for its cancerous transformation may have taken place. In addition, IGF-1Ec expression was significantly higher in non-endometrioid (serous papillary or clear cell) compared with endometrioid endometrial adenocarcinomas, emphasizing the importance of IGF-1Ec expression in the development of non-estrogen dependent carcinomas. Furthermore, expression of IGF-1Ec in the presence of tumoral necrosis in endometrial adenocarcinomas was significantly increased, suggesting an association between IGF-1Ec expression and more aggressive endometrial tumors, as it has been shown that tumoral necrosis 


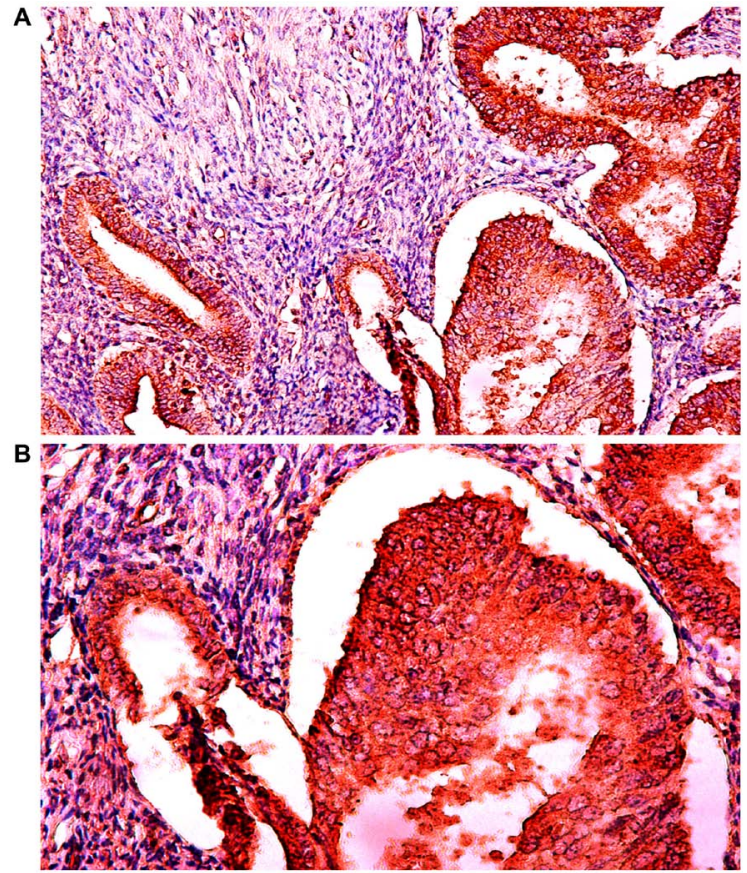

Figure 7. Immunohistochemical expression of IGF-1Ec in complex endometrial hyperplasia with atypia. IGF-1Ec immunohistochemical staining of tissues at a magnification of (A) x200; and (B) x400. IGF-1Ec, insulin-like growth factor-1Ec.

is strongly associated with aggressive behavior of endometrial cancer, and is associated with hypoxia, angiogenesis and inflammation response (116). Furthermore, there was a positive correlation between the sum of staining-intensity and the scores of IGF-1Ec immunopositive cells and the tumor grade of endometrial carcinomas, suggesting that higher expression of IGF-1Ec may contribute to a higher degree of differentiation during endometrial carcinogenesis, and may be associated with the malignant progression in these patients. The molecular pathway of endometrial carcinogenesis is mediated by IGF-1Ec in high-grade uterine endometrioid adenocarcinomas may be similar to that of non-endometrioid (serous papillary and clear cell) endometrial adenocarcinomas. This hypothesis is supported by the active involvement of IGF-1Ec in the carcinogenesis of other types of cancer. In particular, increased expression of IGF-1Ec has been reported in prostate cancer, osteosarcomas, neuroendocrine neoplasms and thyroid carcinomas $(25,100,109,117-119)$. Armakolas et al (109) showed significantly higher expression of IGF-1Ec in prostate tissues and human prostate cancer cell lines compared with normal prostate tissues, and the normal prostate epithelial cells did not express IGF-1Ec. Immunohistochemical analysis from prostate cancer specimens showed that IGF-1Ec expression was significantly positively associated with prostate cancer stage (117). A synthetic analogue of the Ec domain, human $\mathrm{Ec}$, has been shown to promote progression in vitro in human prostate cancer PC-3 cells (118). Philippou et al (100) assessed the expression of IGF-1Ea, IGF-1b and IGF-1Ec isoforms in human osteoblast-like osteosarcoma MG-63 cells, and found that these cells expressed only the IGF-1Ea and IGF-1Ec transcripts. Alexandraki et al (25) investigated IGF-1Ec expression in neuroendocrine neoplasms and found cytoplasmic staining in $49 \%$ (23 out of 47 cases). Furthermore, samples from

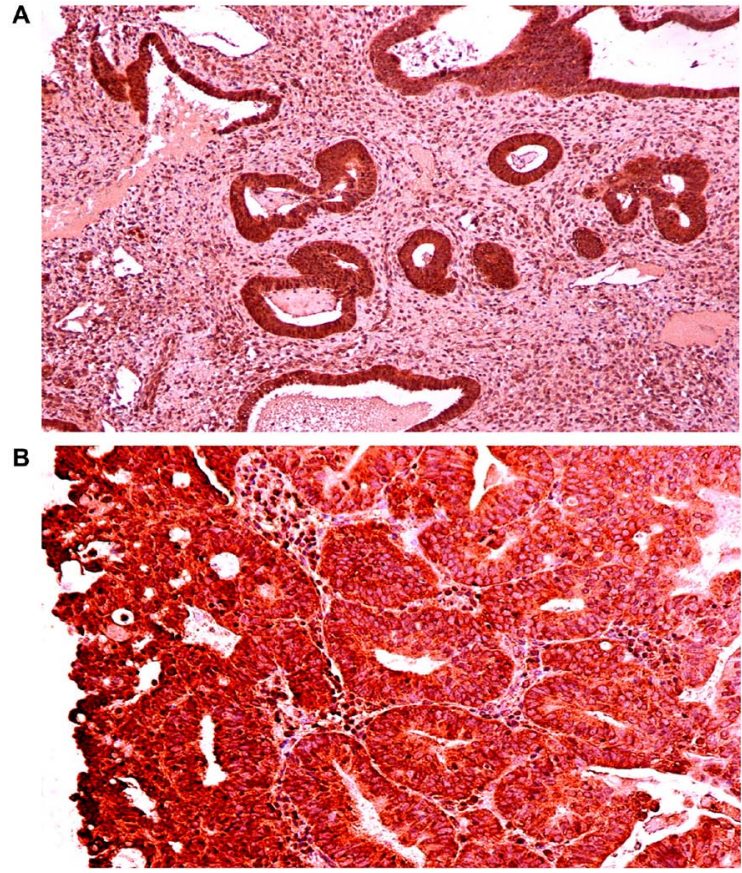

Figure 8. Immunohistochemical expression of IGF-1Ec in simple and complex endometrial hyperplasia. IGF-1Ec immunohistochemical staining of (A) simple endometrial hyperplasia (magnification, x100) and (B) complex endometrial hyperplasia (magnification, x200). IGF-1Ec, insulin-like growth factor-1Ec.

metastatic neuroendocrine neoplasms exhibited significantly higher immunohistochemical expression compared with primary tumors (25). Karagiannis et al (119) investigated the expression of IGF-1Ec in thyroid cancer specimens using immunohistochemistry, and found that the expression of IGF-1Ec was significantly associated with advanced cancer stages, and with muscular and capsule malignant invasion. Together, these findings support the hypothesis that IGF-1Ec expression is directly involved in tumorigenesis, although the exact mechanisms remain to be determined. It has been proposed that Ec domain of the IGF-1Ec isoform may possibly mediate its mitogenic bioactivity through autonomous mechanisms, independent of IGF-1R and IR $(100,109)$. This hypothesis is supported by our findings, showing a strong connection between high levels of IGF-1Ec expression and non-endometrioid endometrial carcinomas, which develop independently from estrogen action.

It has been shown that the IGF-1 pathway serves an important role in the normal proliferation of epithelium and stromal cells in normal menstruating or premenopausal endometrium $(63,120,121)$. IGF-1 and IGF-2 promote cellular growth and differentiation, and act as mediators of steroid hormones (122). Estrogen modulates IGF signaling by increasing the expression of IGF-1 and activation of IGF-1R, whereas progesterone increases the synthesis of IGFBPs to antagonize estrogen-induced cell proliferation (20,27,28,34,64-66). Zhou et al (123) found that endometrial IGF-1 expression was maximal during the proliferative phase, and not in the secretory phase of the menstrual cycle. Results of various studies which evaluated the role of IGF-1 in the biology of endometrial cancer are ambiguous and conflicting (22). Rutanen et al (27) found that the expression of IGFBP-2, IGFBP-4 and IGFBP-5 in endometrial cancer tissues did not differ from those in normal 

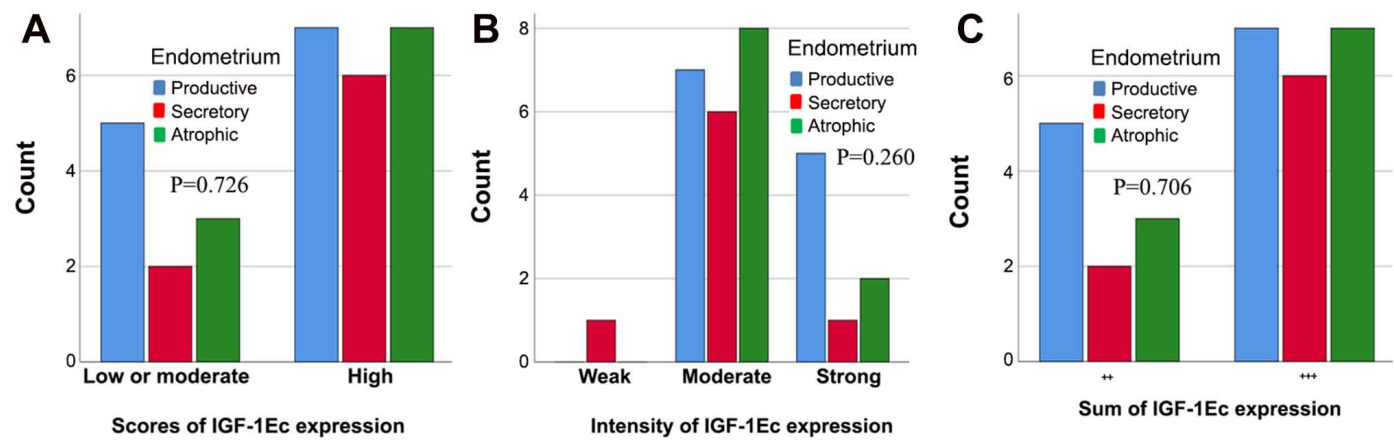

Figure 9. Presentation of IGF-1Ec expression in productive, secretary or atrophic non-neoplastic endometrium. There was no difference in IGF-1Ec expression between the different endometrium categories (productive, secretory and atrophic non-neoplastic) based on the (A) scores $(\mathrm{P}=0.726),(\mathrm{B})$ intensity $(\mathrm{P}=0.260)$ or (C) sum of scores and intensity of immunopositivity $(\mathrm{P}=0.706)$. IGF-1Ec, insulin-like growth factor-1Ec.
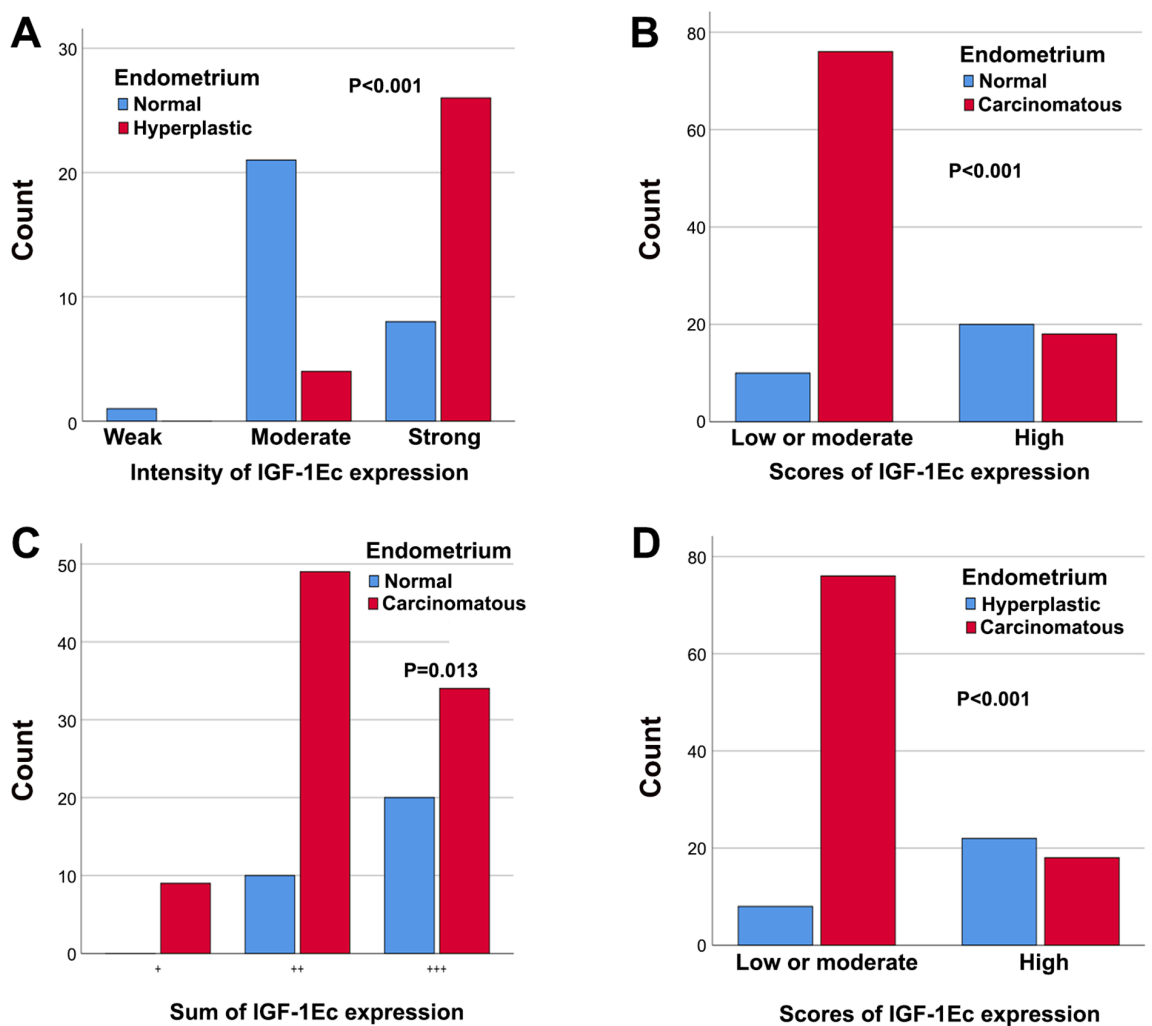

Scores of IGF-1Ec expression
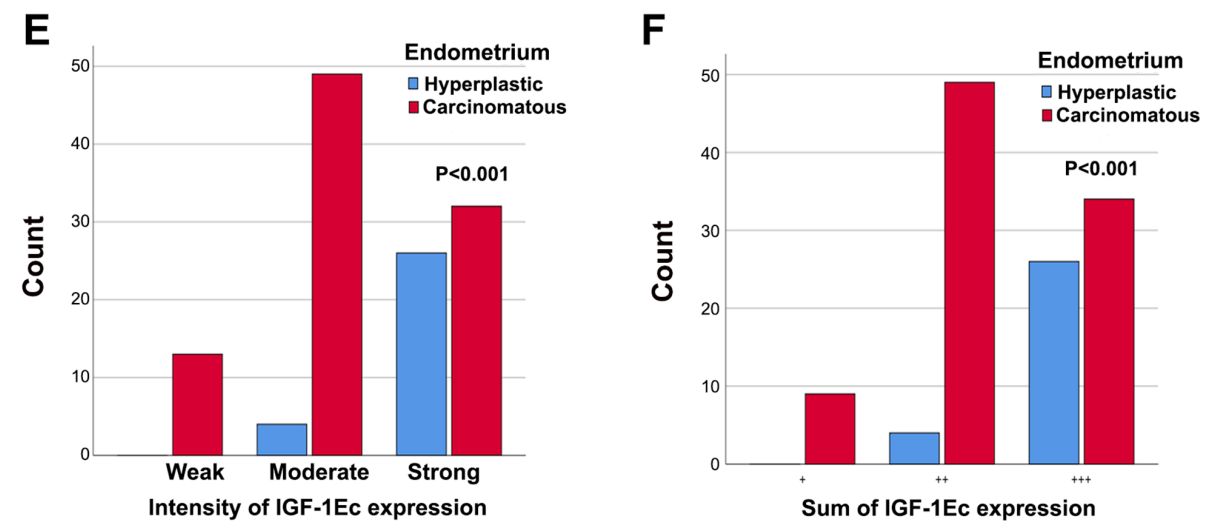

Figure 10. Demonstration of the differences in the levels of IGF-1Ec expression between normal, hyperplastic and carcinomatous endometrium. There was a significant difference in IGF-1Ec expression based on the (A) intensity of IGF-1Ec expression between normal and hyperplastic endometrium (P<0.001); (B) based on the scores of IGF-1Ec expression between normal and carcinomatous endometrium ( $\mathrm{P}<0.001)$; (C) based on the sum of scores and intensity of IGF-1Ec expression between normal and carcinomatous endometrium ( $\mathrm{P}=0.013)$; (D) based on the scores of IGF-1Ec expression between hyperplastic and carcinomatous endometrium $(\mathrm{P}<0.001)$; (E) based on the intensity of IGF-1Ec expression between hyperplastic and carcinomatous endometrium $(\mathrm{P}<0.001)$; and $(\mathrm{F})$ based on the sum of scores and intensity of IGF-1Ec expression between hyperplastic and carcinomatous endometrium (P<0.001). IGF-1Ec, insulin-like growth factor-1Ec. 
A

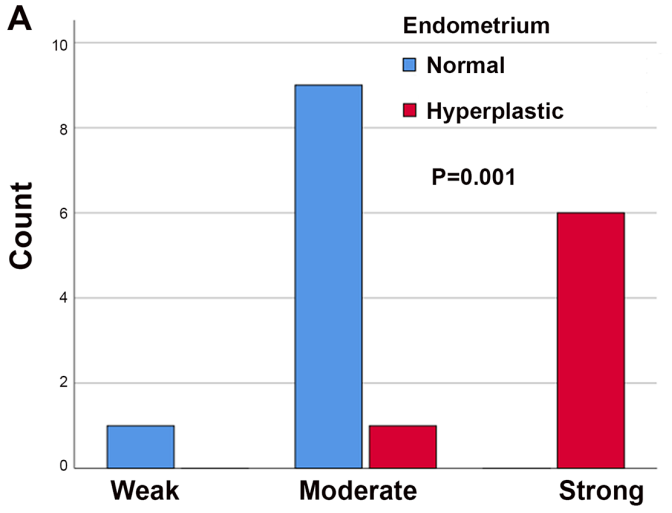

Intensity of IFG-1Ec and p53 co-expression

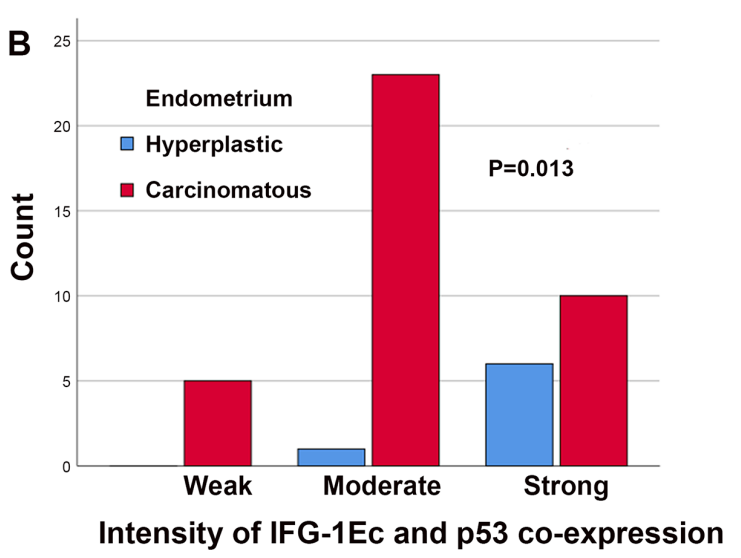

Figure 11. Concurrent IGF-1Ec and p53 expression. There was a statistically significant correlation in the (A) intensity of expression between normal and hyperplastic endometrium $(\mathrm{P}=0.001)$ and $(\mathrm{B})$ in the intensity of expression between hyperplastic and carcinomatous endometrium $(\mathrm{P}=0.013)$. IGF-1Ec, insulin-like growth factor-1Ec.

endometrium. Laatikainen et al (124) found that the expression of IGF-1 was similar in tamoxifen-treated and control patients. Elkas et al (125) found that IGF-1 and IGFBP-1 were expressed in normal and neoplastic endometrium of all patients, regardless of tamoxifen treatment. Mairano et al (126) showed that the levels of IGF-1 and IGF-1R proteins measured by immunohistochemistry were the same between normal and malignant endometrium. However, O'Toole et al (127) found lowered IGF-1, ERa, ERb and progesterone expression in endometrial carcinoma tissues compared with normal premenopausal and postmenopausal endometrial samples. IGF-1 is also modulated by interactions with growth factors (128). Soufla et al (129) showed that IGF-1 and epidermal growth factor (EGF) down-regulation and simultaneous fibroblast growth factor-2 up-regulation may be involved in endometrial carcinogenesis. Furthermore, it has been shown that upregulation of IGF-1R is correlated with expression of VEGF factor $\mathrm{C}$ and this may be important in lymph node metastasis in patients with endometrial adenocarcinoma (130).

PTEN is a tumor suppressor gene which modulates cell proliferation and cell survival, and is frequently mutated or deleted in several types of cancer. PTEN functions as a lipid phosphatase and serves a key role in regulation of the PI3 kinase/Akt pathway. The IGF system serves an important role in cell proliferation and cell survival via the PI3 kinase/AKT
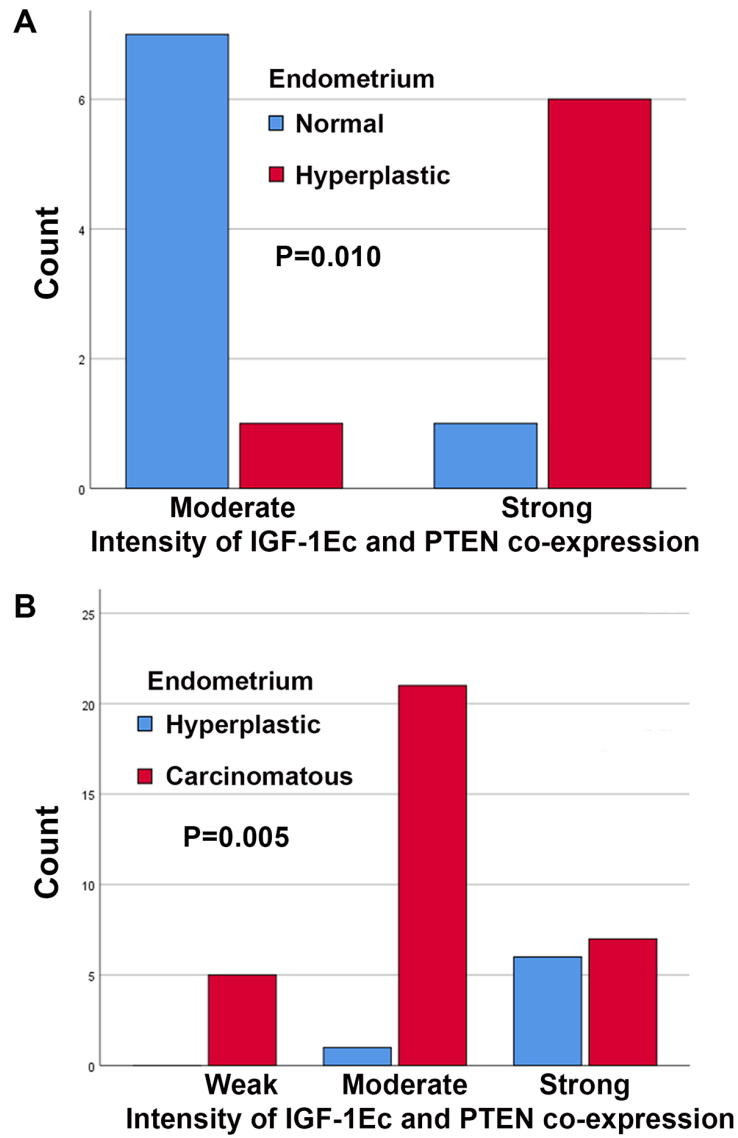

Figure 12. Concurrent IGF-1Ec and PTEN expression. There was a statistically significant correlation in the intensity of expression between (A) normal and hyperplastic endometrium $(\mathrm{P}=0.010)$ and $(\mathrm{B})$ between hyperplastic and carcinomatous endometrium $(\mathrm{P}=0.005)$. IGF-1Ec, insulin-like growth factor-1Ec; PTEN, phosphatase and tensin homologue deleted on chromosome 10 .

and MAP kinase pathways in several neoplasmatic cells. In human gastric adenocarcinoma cells, Yi et al (131) suggested that PTEN may inhibit the anti-apoptotic properties of IGF. PTEN may block IGF-IGFR-induced Akt activity and may also regulate the expression of members of the IGF system, in particular through up-regulation of IGFBP-3. The association between IGF-1R activation status and PTEN expression status in cases of complex atypical endometrial hyperplasia and endometrial carcinoma were investigated by McCamplell et al (132), who suggested that elevated levels of activated IGF-1R and concomitant PTEN may be associated with an increased risk of either endometrial carcinoma or subsequent development of endometrial carcinoma. In endometrial cancer cells, Dong et al (133) showed that picropodophyllin, an IGF-1R inhibitor in the growth of endometrial cancer, resulted in down-regulation of IGF-1R phosphorylation and reduced cell proliferation via the PI3K/Akt signaling pathway. In the present study, there was a negative association between the proportion of immunopositive cells (scores) or the sum of staining (scores and intensity) and the coexistence of IGF-1Ec and PTEN expression. Thus, IGF-1Ec and PTEN may work in opposite directions from each other during endometrial carcinogenesis. These findings suggest that cases with high IGF-1Ec staining score show decreased scores of PTEN staining scores and vice versa. The molecular mechanism underlying this negative 
A

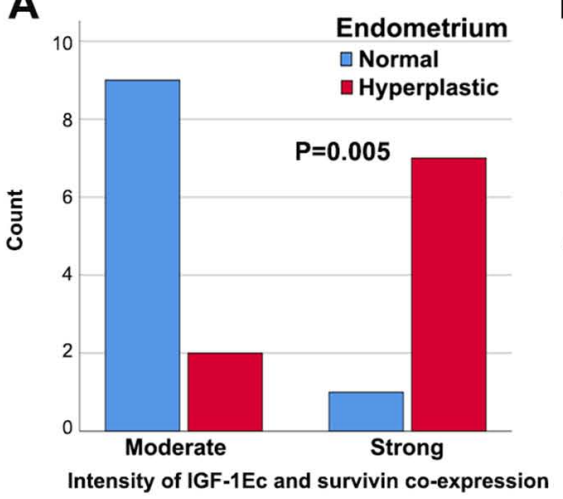

B

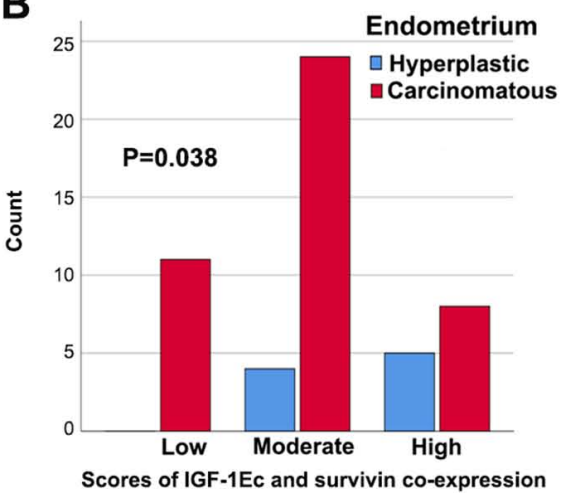

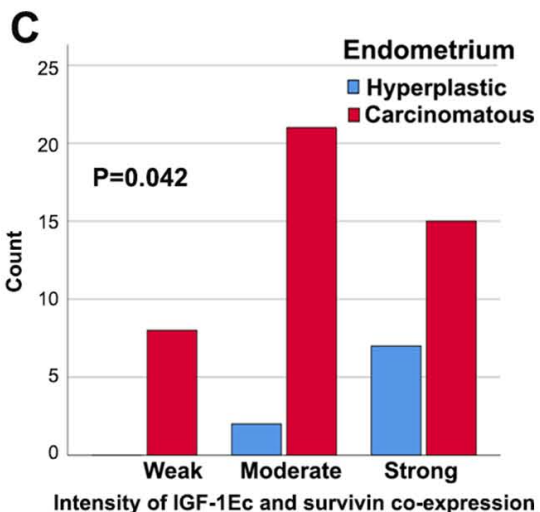

Figure 13. Concurrent IGF-1Ec and survivin expression. There was a statistically significant correlation in the intensity of expression between (A) normal and hyperplastic endometrium $(\mathrm{P}=0.005)$; $(\mathrm{B})$ in the scores of expression between hyperplastic and carcinomatous endometrium $(\mathrm{P}=0.038)$; $(\mathrm{C})$ in the intensity of expression between hyperplastic and carcinomatous endometrium $(\mathrm{P}=0.042)$. IGF-1Ec, insulin-like growth factor-1Ec.

association between these two mediators of apoptosis remains to be determined. There was, a significant association between the intensity of IGF-1Ec and PTEN positivity with the histological type or the presence of lymph-vascular space invasion. Therefore, these findings suggest that the opposite relationship between IGF-1Ec and PTEN may result in a worse prognosis during endometrial carcinogenesis.

The nuclear transcript p53 is a tumor suppressor gene with strong apoptotic effects. There is considerable evidence showing the interplay between the IGF signaling pathway and the tumor suppressor gene $\mathrm{p} 53$. In prostate cancer cell lines in vitro, Leung et al (134) suggested IGF-1 was potentially down-regulated by p53. Tucci (135) suggested a potential association between p53 and IGF-1 signaling pathways in dietary caloric restriction-induced life extension; p53 may regulate longevity via TOR/insulin/IGF-1 signaling. Luo et al (136) showed that prolonged activation of IGF-1 signaling enhanced ameliorative hepatic steatosis and fibrogenesis via inhibition of nuclear p53-progerin interaction. A possible molecular connection between p53 and IGF-1 was also suggested by Tran et al (137) involving IGF-1-SIRT1-p53 signaling in cellular senescence and aging. Attias-Geva et al (138) assessed the involvement of p53 in regulation of IGF-1R gene expression in uterine serous carcinoma cell lines and found that wild type p53 repressed the IGF-1R promoter. In the present study, there was no association between the concomitant expression of IGF-1Ec and p53. However, there was a significant association between the concomitant IGF-1Ec and p53 stain intensity or the sum of their scores and staining intensity with the histological type and/or the histological grade of endometrial carcinomas; non-endometrioid carcinomas or Grade 3 endometrial adenocarcinomas showed concomitant high IGF-1Ec and p53 immunostaining. These results suggest that the co-expression of IGF-1Ec and p53 serves an important role in the development of non-endometrioid or high-grade endometrial adenocarcinoma.

Survivin is a unique member of the inhibitor of apoptosis family of proteins, and regulates cell proliferation. Survivin is upregulated in the majority of human tumors through poorly defined mechanisms (139-144). Additionally, activation of the Stat 3 transcription pathway determines the radio-sensitivity of cancer cells (145). In hepatocellular carcinoma cell lines it has been shown that IGF-1 and survivin are able to co-regulate metastasis; surviving may serve a vital role in the IGF-1 signaling pathway by mediating epithelial-mesenchymal transition (EMT) through the up-regulation of the expression of EMT markers, and the knockdown of surviving expression may suppress metastasis of cancer cells (78). In addition, in prostate cancer cells a positive correlation between IGF and survivin was observed. IGF-1/mTOR signaling may increase survivin-expression via rapid changes in mRNA translation (146). Furthermore, in rat prostatic epithelial cells, it has been shown that IGF-1 signaling increased the expression of survivin via a PI3K/Akt/mTOR1 pathway and promoted cell growth by suppressing Smad-dependent autocrine transforming growth factor- $\beta$ signaling (147). In renal cell lines, Sato et al (148) suggested that cell proliferation and survivin expression were induced by IGF-1. In pancreatic cancer cells, IGF-1 may promote radio-resistance through activation of the Stat3 pathway (145). Oh et al (149) suggested that treatment with a farnesyltransferase inhibitor in head and neck squamous cell carcinoma and non-small cell lung cancer cell lines activated the IGF-1R/PI3-kinase/Akt signaling pathway, leading to increased mTOR-mediated protein synthesis of survivin. Morgillo et al (150) suggested that enhanced synthesis of survivin protein mediated by the IGF-1R/EGFR heterodimer counteracts the antitumor action of erlotinib, an EGFR tyrosine kinase inhibitor in human NSCLC cell lines. In particular, erlotinib induced heterodimerization of IGF-1R/EGFR, and stimulated the IGF-1R and PI3K/Akt/mTOR1 pathways resulting in an increase in EGFR and survivin protein expression; however, assessment of combined treatment with erlotinib and inhibitors of IGF-1R or mTOR resulted in suppression of survivin and EGFR expression (150). In the present study, a positive association was observed between the sum of staining (scores and intensity) and the coexistence of IGF-1Ec and survivin expression. Thus, IGF-1Ec and survivin may promote endometrial carcinogenesis together, regulating in parallel each other's actions, and therefore may share a common molecular pathway. In addition, in the present study, there was an association between the scores of immunohistochemical concomitant expression of IGF-1Ec and survivin and the clinical stage, histological differentiation, lymph-vascular space invasion and the presence of tumoral necrosis. Furthermore, in the case of concomitant expression of IGF-1Ec and survivin, the sum 
of scores and staining intensity of immunopositive cells was associated with the histological differentiation, or the presence of tumoral necrosis. These results suggest the importance of further studying the coexistence of IGF-1Ec and survivin in the development of more aggressive endometrial carcinomas.

The development of endometrial adenocarcinoma is complicated and is based on multiple steps. The mapping of IGF-1Ec in normal, hyperplastic and malignant endometrium allows for a better understanding of endometrial carcinogenesis. Continuous endometrial stimulation of IGF-1Ec with concomitant expression of PTEN, p53 and survivin may initiate uncontrolled cell proliferation and result in malignant transformation. The results of the present study highlight the importance of IGF-1Ec expression in the progression of endometrial carcinoma, which progresses from normal endometrium to hyperplasia and then on to carcinoma. In addition, the different levels of IGF-1Ec expression in normal, hyperplastic and malignant endometrium, and the synergistic action of IGF-1Ec with p53, PTEN or survivin observed in the present study support the autocrine and/or paracrine role with growth factors, survival factors, oncogenes and/or tumor suppressor genes during the endometrial pathophysiology.

The upregulated expression of IGF-1Ec in non-endometrioid (serous papillary or clear cell) compared with endometrioid adenocarcinomas emphasize the importance of IGF-1Ec expression in the development of non-estrogen dependent carcinomas. Furthermore, the upregulated expression of IGF-1Ec in the presence of tumoral necrosis in endometrial adenocarcinomas suggest an association between IGF-1Ec expression and more aggressive endometrial tumors. The present study showed that upregulation of IGF-1Ec is associated with a high histological grade in endometrial carcinoma, and supports the hypothesis that IGF-1Ec serves an important role in differentiation and progression of endometrial carcinogenesis. Additionally, the present study is the first to show that the molecular pathway of endometrial carcinogenesis is similar between high grade and non-endometrioid (serous papillary and clear cell) uterine endometrial adenocarcinomas; and this pathway may be activated by the IGF-1Ec upregulation. These results suggest that higher levels of IGF-1Ec expression are associated with more aggressive behavior in endometrial adenocarcinomas. These findings reflect the biological behavior and spreading patterns of endometrial carcinomas which may in turn allow for more accurate prognostic prediction. Although our study shows for the first time a potential role of high scores of IGF-1Ec in non-endometrioid (serous papillary or clear cell) compared to endometrioid endometrial carcinomas, it also has a number of limitations including the relative low number of studied cases of clear cell and serous papillary compared to endometrioid adenocarcinomas (13 vs. 86 cases, respectively). In addition, the experimental design of our study did not allow fresh frozen endometrial tissue collection for analysis of the IGF-1Ec mRNA expression. Furthermore, the research design of the present study did not consider the examination of hormone receptor expression in endometrial tumors for confirmation of our statement on hormone-insensitivity.

In conclusion, the concomitant expression between IGF-1Ec and PTEN, p53 and survivin highlights the molecular mechanisms which may be involved in endometrial carcinogenesis. IGF-1Ec and PTEN may act together opposing direction from each other during endometrial carcinogenesis.
The inverse association between the intensity of IGF-1Ec and PTEN positivity, and the histological type and the presence of lymph-vascular space invasion may suggest a regulatory role of IGF-1Ec in modulating PTEN expression, resulting in a worse prognosis during endometrial carcinogenesis. In contrast, the positive correlation between IGF-1Ec and survivin suggests that these molecules may share a common molecular pathway, and may act in parallel as potential mediators during endometrial carcinogenesis. A combination of high positive levels of IGF-1Ec expression and survivin expression was associated with a high clinical stage, high grade of histological differentiation, presence of lymph-vascular space invasion and presence of tumoral necrosis. These findings suggest that IGF-1Ec and survivin work cooperatively resulting in the development of more aggressive endometrial carcinomas. Finally, the association between the concomitant IGF-1Ec and p53 staining intensity or the sum of their scores and staining intensity, and the histological types or the histological grade was shown. It is hypothesized that the concomitant upregulation of IGF-1Ec and p53 serves an important role in the development of non-endometrioid endometrial carcinomas and in the progression to high grade endometrial tumors.

\section{Acknowledgements}

The present study is part of a thesis for a Doctor of Philosophy $(\mathrm{PhD})$ in Obstetrics and Gynecology, Medical School, Kapodistrian University of Athens, Greece for Mr. Aggelis Stavropoulos

\section{Funding}

Not applicable.

\section{Availability of data and materials}

The datasets used and/or analyzed during this study are available from the corresponding author on reasonable request.

\section{Authors' contributions}

TV and AT were responsible for the provision of the study materials. TV, AT, VKV and FNV were responsible for the collection and assembly of the data. AS, MV, AP, TV, VKV, FNV, AT, ACL and MK performed the data analysis and interpretation. AS, MV, AP, TV, VKV, FNV, AT, ACL and MK contributed to the writing, drafting, revising, editing, reviewing and the conception and design of the study. All authors read and approved the final manuscript.

\section{Ethics approval and consent to participate}

The study was approved by the Ethics Committee of Medical School of Kapodistrian University of Athens, Greece. All patients provided written informed consent before the study for participation.

\section{Patient consent for publication}

All patients included in this study at the time of data collection provided consent for their data to be used in this publication. 


\section{Competing interests}

The authors declare that they have no competing interests.

\section{References}

1. Creasman WT, Odicine F, Maisonneuve P, Quinn MA, Beller U, Benedet JL, Heintz AP, Ngan HY and Pecorelli S: Carcinoma of the corpus uteri. FIGO 26th annual report on the results of treatment in gynecological cancer. Int J Gynaecol Obstet 95 (Suppl 1): S105-S143, 2006.

2. Jemal A, Siegel R, Xu J and Ward E: Cancer statistics, 2010. CA Cancer J Clin 60: 277-300, 2010.

3. Doll A, Abal M, Rigau M, Monge M, Gonzalez M, Demajo S, Colás E, Llauradó M, Alazzouzi H, Planagumá J, et al: Nove molecular profiles of endometrial cancer-new light through old windows. J Steroid Biochem Mol Biol 108: 221-229, 2008.

4. Bray F, Dos Santos Silva I, Moller H and Weiderpass E: Endometrial cancer incidence trends in Europe: Underlying determinants and prospects for prevention. Cancer Epidemiol Biomarkers Prev 14: 1132-1142, 2005.

5. Kourea HP, Nikolaou M, Tzelepi V, Adonakis G, Kardamakis D, Tsapanos V, Scopa CD, Kalofonos C and Decavalas G: Expression of phosphorylated Akt, mTOR and MAPK in type I endometrial carcinoma: Clinical significance. Anticancer Res 35: 2321-2331, 2015.

6. Shevra CR, Ghosh A and Kumar M: Cyclin D1 and Ki-67 expression in normal, hyperplastic and neoplastic endometrium. J Postgrad Med 61: 15-20, 2015.

7. Morice P, Leary A, Creutzberg C, Abu-Rustum N and Darai E Endometrial cancer. Lancet 387: 1094-1108, 2016.

8. Takeshita S, Yamashita Y, Shiomi K, Suzuki N, Yoshida J, Naiki-Ito A, Suzuki S, Akatsuka S, Toyokuni S, Takahashi T, et al: Expression of P-REX2a is associated with poor prognosis in endometrial malignancies. Oncotarget 9: 24778-24786, 2018.

9. Bokhman JV: Two pathogenetic types of endometrial carcinoma. Gynecol Oncol 15: 10-17, 1983.

10. Parazzini F, La Vecchia C, Bocciolone L and Franceschi S: The epidemiology of endometrial cancer. Gynecol Oncol 41: 1-16, 1991.

11. Steiner E, Eicher O, Sagemuller J, Schmidt M, Pitch H, Tanner B, Hengstler JG, Hofmann $M$ and Knapstein PG Multivariate independent prognostic factors in endometrial carcinoma: A clinicopathological study in 181 patients: 10 experience at the department of obstetrics and gynecology of the mainz university. Int J Gynecol Cancer 13: 197-203, 2003.

12. Prat J. Prognostic parameters of endometrial carcinoma. Hum Pathol 35: 649-662, 2004

13. Daughaday WH and Rotwein P: Insulin-like factors I and II. Peptide, messenger ribonucleic acid and gene structures, serum and tissue concentrations. Endocr Rev 10: 68-91, 1989.

14. De Meyts P and Whittaker J: Structural biology of insulin and IGF1 receptors: Implications for drug design. Nat Rev Drug Discov 1: 769-783, 2002.

15. Federici M Porzio O, Zucaro L, Giovannone B, Borboni P, Marini MA, Lauro D and Sesti G: Increased abundance of insulin/IGF-I hybrid receptors in adipose tissue from NIDDM patients. Mol Cell Endocrinol 135: 41-47, 1997.

16. Nakae J, Kido Y and Accili D: Distinct and overlapping functions of insulin and IGF-I receptors. Endocr Rev 22: 818-835, 2001.

17. Baserga R, Peruzzi F and Reiss K: The IGF-1 receptor in cancer biology. Int J Cancer 107: 873-877, 2003.

18. Taguchi A and White MF: Insulin-like signaling, nutrient homeostasis, and life span. Annu Rev Physiol 70: 191-212, 2008

19. Samani AA, Yakar S, LeRoith D and Brodt P: The role of the IGF system in cancer growth and metastasis: Overview and recent insights. Endocr Rev 28: 20-47, 2007.

20. Milingos DS, Philippou A, Armakolas A, Papageorgiou E, Sourla A, Protopapas A, Liapi A, Antsaklis A, Mastrominas M and Koutsilieris M: Insulin-like growth factor-1Ec (MGF) expression in eutropic and ectopic endometrium: Characterization of the MGF E-peptide actions in vitro. Mol Med 17: 21-28, 2011.

21. Jones JI and Clemmons DR: Insulin-like growth factors and their binding proteins: Biological actions. Endocr Rev 13: 3-34, 1995.

22. Majchrzak-Baczmańska D and Malinowski A: Does IGF-1 play a role in the biology of endometrial cancer? Ginekol Pol 87: 598-604, 2016
23. Flannery CA, Saleh FL, Choe GH, Selen DJ, Kodaman PH, Kliman HJ, Wood TL and Taylor HS: Differential expression of IR-A, IR-B and IGF-1R in endometrial physiology and distinct signature in adenocarcinoma. J Clin Endocrinol Metab 101: 2883-2891, 2016.

24. Dai C, Li N, Song G, Yang Y and Ning X: Insulin-like growth factor 1 regulates growth of endometrial carcinoma through PI3k signaling pathway in insulin-resistant type 2 diabetes. Am J Transl Res 8: 3329-3336, 2016.

25. Alexandraki KI, Philippou A, Boutzios G, Theohari I, Koutsilieris M, Delladetsima IK and Kaltsas GA: IGF-IEc expression is increased in secondary compared to primary foci in neuroendocrine neoplasms. Oncotarget 8: 79003-79011, 2017.

26. Mazerbourg S and Monget P: Insulin-like growth factor binding proteins and IGFBP proteases: A dynamic system regulating the ovarian folliculogenesis. Front Endocrinol (Lausanne) 9: 134, 2018.

27. Rutanen EM, Nyman T, Lehtovirta P, Ammala M and Pekonen F Suppressed expression of insulin-like growth factor binding protein-1 mRNA in the endometrium: A molecular mechanism associating endometrial cancer with its risk factors. Int J Cancer 59: 307-312, 1994.

28. Suvanto-Luukkonen E, Sundostrom H, Penttinen J, Kauppila A and Rutane EM: Insulin-like growth factor-binding protein-1: A biochemical marker of endometrial response to progestin during hormone replacement therapy. Maturitas 22: 255-262, 1995.

29. Vassilakos G, Philippou A, Tsakiroglou P and Koutsilieris M: Biological activity of the e domain of the IGF-1Ec as addressed by synthetic peptides. Hormones (Athens) 13: 182-196, 2014.

30. Philippou A, Maridaki M, Pneumaticos S and Koutsilieris $M$ The complexity of the IGF1 gene splicing, posttranslational modification and bioactivity. Mol Med 20: 202-214, 2014

31. Kornfeld S: Structure and function of the mannose-6-phosphate/insulinlike growth factor II receptors. Annu Rev Biochem 61: 307-330, 1992.

32. LeRoith D and Roberts CT Jr: The insulin-like growth factor system and cancer. Cancer Lett 195: 127-137, 2003.

33. Baxter RC and Martin JL: Binding proteins for the insulin-like growth factors: Structure, regulation and function. Prog Growth Factor Res 1: 49-68, 1989.

34. Murphy LJ and Ghahary A: Uterine insulin-like growth factor-1: Regulation of expression and its role in estrogen-induced uterine proliferation. Endocr Rev 11: 443-453, 1990.

35. $\mathrm{Yu} \mathrm{H}$ and Rohan $\mathrm{T}$ : Role of the insulin-like growth factor family in cancer development and progression. J Natl Cancer Inst 92: $1472-1489,2000$

36. Mourmouras N, Philippou A, Christopoulos P, Kostoglou K, Grivaki C, Konstantinidis C, Serafetinides E, Delakas D and Koutsilieris M: Different expression of IGF-I transcripts in bladder cancer. Anticancer Res 38: 3453-3459, 2018

37. Kelley KM Oh Y, Gargosky SE, Gucev Z, Matsumoto T, Hwa V, $\mathrm{Ng}$ L, Simpson DM and Rosenfeld RG: Insulin-like growth factor-binding proteins (IBFBPs) and their regulatory dynamics. Int J Biochem Cell Biol 28: 619-637, 1996.

38. Clemmons DR: Insulin-like growth factor binding proteins and their role in controlling IGF actions. Cytokine Growth Factor Rev 8: 45-62, 1997.

39. Burroughs KD, Donn SE, Barrett JC and Taylor JA: Insulin-like growth factor-I: A key regulator of human cancer risk? J Natl Cancer Inst 91: 579-581, 1999.

40. Adamo ML, Ben-Hur H, LeReith D and Roberts CT Jr: Transcription initiation in the two leader exons of the rat IGF-1 gene occurs from disperse versus localized sites. Biochem Biophys Res Commun 176: 887-893, 1991.

41. Adamo ML, Neuenschwander S, LeRoith D and Roberts CT Jr: Structure, expression, and regulation of the IGF-I gene. Adv Exp Med Biol 343: 1-11, 1993.

42. Adamo ML: Regulation of insulin-like growth factor I gene expression. Implications for normal and pathological growth. Diabetes Rev 3: 2-27, 1995.

43. Simmons JG, Van Wyk JJ, Hoyt EC and Lund PK: Multiple transcription start sites in the rat insulin-like growth factor-I gene give rise to IGF-I mRNAs that encode different IGF-I precursors and are processed differently in vitro. Growth Factors 9: 205-221, 1993.

44. Bell GI, Stempien MM, Fong NM and Rall LB: Sequences of liver cDNAs encoding two different mouse insulin-like growth factor 1 precursors. Nucleic Acids Res 14: 7873-7882, 1986.

45. Temmerman L, Slonimsky E and Rosenthal N: Class 2 IGF-1 isoforms are dispensabile for viability, growth and maintenance of IGF-1 serum levels. Growth Horm IGF Res 20: 255-263, 2010 
46. Matheny RW Jr, Nindl BC and Adamo ML: Minireview: Mechano-growth factor: A putative product of IGF-I gene expression involved in tissue repair and regeneration. Endocrinology 151: $865-875,2010$

47. Kasprzak A, Szaflarski W, Szmeja J, Andrzejewska M, Przybyszewska W, Kaczmarek E, Koczorowska M, Kościński T, Zabel $\mathrm{M}$ and Drews M: Differential expression of IGF-1 mRNA isoforms in colorectal carcinoma and normal colon tissue. Int J Oncol 42: 305-316, 2013.

48. Philippou A, Armakolas A and Koutsilieris M: Evidence for the possible biological significance of the igf-1 gene alternative splicing in prostate cancer. Front Endocrinol (Lausanne) 4: 31 , 2013.

49. Jansen M, van Schaik FM, Richer AT, Bullock B Woods DE, Gabbay KH, Nauubaum AL, Sussenbach JS and Van den Brande JL: Sequence of cDNA encoding human insulin-like growth factor I precursor. Nature 306: 609-611, 1983

50. Brisson BK, Spinazzola J, Park S and Barton ER: Viral expression of insulin-like growth factor I E-peptide increases skeletal muscle mass but at the expense of strength. Am J Physiol Endocrinol Metab 306: E965-E974, 2014.

51. Rotwein P, Pollock KM, Didier DK and Krivi GG: Organization and sequence of the human insulin-like growth factor I gene. Alternative RNA processing produces two insulin-like growth factor I precursor peptides. J Biol Chem 261: 4828-4832, 1986

52. Duguay SJ: Post-translational processing of insulin-like growth factors. Horm Metab Res 31: 43-49, 1999.

53. Barton ER: The ABCs of IGF-I isoforms: Impact on muscle hypertrophy and implications for repair. Appl Physiol Nutr Metab 31: 791-797, 2006

54. Wallis M: New insulin-like growth factor (IGF)-precursor sequences from mammalian genomes: The molecular evolution of IGFs and associated peptides in primates. Growth Horm IGF Res 19: 12-23, 2009.

55. Siegfriend JM, Kasprzyk PG, Treston AM, Mulshine JL Quinn KA and Cuttitta F: A mitogenic peptide amide encoded within the E peptide domain of the insulin-like growth factor IB prohormone. Proc Natl Acad Sci USA 89: 8107-8111, 1992.

56. Kuo YH and Chen TT: Novel activities of pro-IGF-I E peptides: Regulation of morphological differentiation and anchorage-independent growth in human neuroblastoma cells. Exp Cell Res 280: 75-89, 2002.

57. Chew SL, Lavender P, Clark AJ and Ross RJ: An alternatively spliced human insulin-like grow th factor-1 transcript with hepatic tissue expression that diverts away from mitogenic IBE1 peptide. Endocrinology 136: 1939-1944, 1995.

58. Tian XC, Chen MJ, Pantschenko AG, Yang TJ and Chen TT: Recombinant E-peptides of pro-IGF-I have mitogenic activity. Endocrinology 140: 3387-3390, 1999.

59. Chen MJ, Chiou PP, Lin P, Lin CM, Siri S, Peck K and Chen TT: Suppression of growth and cancer-induced angiogenesis of aggressive human breast cancer cells (MDA-MB-231) on the chorionallantoic membrane of developing chicken embryos by E-peptide of pro-IGF-I. J Cell Biochem 101: 1316-1327, 2007.

60. Armakolas A, Dimakakos A, Loucogiannaki C, Armakolas N, Antonopoulos A, Florou C, Tsioli P, Papageorgiou E, Alexandrou TP, Stathaki M, et al: IL-6 is associated to IGF-1Ec upregulation and Ec peptide secretion, from prostate tumors. Mol Med 24: 6, 2018.

61. Garrouste F, Remacle-Bonnet M, Fauriat C, Marvaldi J, Luis J and Pommier G: Prevention of cytokine-induced apoptosis by insulin-like growth factor-I is independent of cell adhesion molecules ijn HT29-D4 colon carcinoma cells-evidence for a NF-kappaB-dependent survival mechanism. Cell Death Differ 9: 768-779, 2002

62. Alexia C, Fallot G, Lasfer M, Schweizer-Groyer G and Groyer A: An evaluation of the role of insulin-like growth factors (IGF) and of type-I IGF receptor signaling in hepatocarcinogenesis and in the resistance of hepatocarcinoma cells against drug-induced apoptosis. Biochem Pharmacol 86: 1003-1015, 2004.

63. Wang HS and Chard T: IGFs and IGF-binding proteins in the regulation of human ovarian and endometrial function. J Endocrinol 161: 1-13, 1999.

64. BogdanosJ,KaramanolakisD,TentaR,Tsintavis A,MilathianakisC, Mitsiades C and Koutsilieris M: Endocrine/paracrine/autocrine survival factor activity of bone microenviroment participates in the development of androgen ablation and chemotherpay refractoriness of prostate cancer metastasis in skeleton. Endocr Relat Cancer 10: 279-289, 2003.

65. Koutsilieris M: Pathophysiology of uterine leiomyomas. Biochem Cell Biol 70: 273-278, 1992.
66. Koutsilieris M, Mitsiades C and Sourla A: Insulin-like growth factor I and urokinase-type plasminogen activator bioregulation system as a survival mechanism of prostate cancer cells in osteoblastic metastases: Development of anti-survival factor therapy for hormone-reflactory prostate cancer. Mol Med 6: 251-267, 2000.

67. Hernandez AV, Pasupuleti V, Benites-Zapata VA, Thota P, Deshpande A and Perez-Lopez FR: Insulin resistance and endometrial cancer risk: A systemic review and meta-analysis. Eur J Cancer 51: 2747-2758, 2015.

68. Pavelic J, Radakovic B and Pavelic K: Insulin-like growth factor 2 and its receptors (IGF $1 \mathrm{R}$ and IGF $2 \mathrm{R} /$ mannose 6-phospate) in endometrial adenocarcinoma. Gynecol Oncol 105: 727-735, 2007.

69. Stavropoulos A, Varras M, Vasilakaki T, Varra VK, Tsavari A, Varra FN, Nonni A, Kavantzas N and Lazaris AC: Expression of p53 and PTEN in human primary endometrial carcinomas: Clinicopathological and immunohistochemical analysis and study of their concomitant expression. Oncol Lett 17: 4575-4589, 2019.

70. Stavropoulos A, Varras M, Vasilakaki T, Varra VK, Varra FN, Tsavari A, Nonni A, Kavantzas N and Lazaris AC: Expression of anti-apoptotic protein survivin in human endometrial carcinoma: Clinical and pathological correlations as a separate factor and in combination with concomitant PTEN and p53 expression. Oncol Lett 20: 1033-1054, 2020.

71. Galimi F, Torti D, Sassi F, Isella C, Corà D, Gastaldi S, Ribero D, Muratore A, Massucco P, Siatis D, et al: Genetic and expression analysis of MET, MACC1, and HGF in metastatic colorectal cancer: Response to met inhibition in patient xenografts and pathologic correlations. Clin Cancer Res 17: 3146-3156, 2011

72. Li M, Xin X, Wu T, Hua T, Wang H and Wang H: Stromal cells of endometrial carcinoma promotes proliferation of epithelial cells through the HGF/c-Met/Akt signaling pathway. Tumour Biol 36: 6239-6248, 2015

73. Harpaz N, Taboada S, Ko HM, Yu J, Yang Q, Xu H and Cao W: Expression of MACC1 and MET in inflammatory bowel disease-associated colonic neoplasia. Inflamm Bowel Dis 20: 703-711, 2014.

74. Zhang Q, Xu P, Lu Y and Dou H: Correlation of MACC1/c-Myc expression in endometrial carcinoma with clinical/pathlogical features or prognosis. Med Sci Monit 24: 4738-4744, 2018.

75. Yang E and Yan H: Expression of ELF5 in endometrial carcinoma tissues and its clinical significance. Oncol Lett 16: 3473-3480, 2018.

76. Singh N, Hirschowitz L, Zaino R, Alvarado-Cabrero I, Duggan MA, Ali-Fehmi R, Euscher E, Hecht JL, Horn LC, Ioffe $\mathrm{O}$, et al: Pathologic prognostic factors in endometrial carcinoma (other than tumor type and grade). Int J Gynecol Pathol 38 (Suppl 1): S93-S113, 2019.

77. Sadlecki P, Bodnar M, Grabiec M, Marszalek A, Walentowicz P, Sokup A, Zegarska J and Walentowicz-Sadlecka M: The role of Hypoxia-inducible factor-1 $\alpha$, Glucose thransporter-1, (GLUT-1) and carbon anhydrase IX in endometrial cancer patients. Biomed Res Int 2014: 616850, 2014.

78. Liu F, Sun Y, Liu B, Lu J, Li H, Zhu H, Gao H, Zhou X and Chang H: Insulin-like growth factor-1 induces epithelial-mesenchymanl transition in hepatocellular carcinoma by activating survivin. Oncol Rep 40: 952-958, 2018.

79. Bansal N, Yendluri V and Wenham RM: The molecular biology of endometrial cancers and the implications for pathogenesis, classification, and targeted therapies. Cancer Control 16: 8-13, 2009.

80. Llauradó M, Ruiz A, Majem B, Ertekin T, Colás E, Pedrola N, Devis L, Rigau M, Sequeiros T, Montes M, et al: Molecular bases of endometrial cancer: New roles for new actors in the diagnosis and the therapy of the disease. Mol Cell Endocrinol 358: 244-255, 2012.

81. Meng X, Dizon DS, Yang S, Wang X, Zhu D, Thiel KW and Leslie KK: Strategies for molecularly enhanced chemotherpay to achieve synthetic lethality in endometrial tumors with mutant p53. Obstet Gynecol Int 2013: 828165, 2013.

82. Sugihara T: Loss of adherens junction protein E-cadherin is a biomarker of high grade histology and poor prognosis in endometrial cancer. Ann Clin Lab Res 4: 1, 2016.

83. Gómez-Macías GS, Garza-Rodríguez ML, Garza-Guajardo R, Monsiváis-Ovalle D, Ancer-Rodríguez J, Barrera-Saldaña HA and Barboza-Quintana O: Overexpression of the matrix metalloproteinase 11 gene is a potential biomarker for type 1 endometrial cancer. Oncol Lett 16: 1073-1078, 2018.

84. Buchynska LG, Brieiva OV and Iurchenko NP: Assessment of HER-2/neu, c-MYC and CCNE1 gene copy number variations and protein expression in endometrial carcinomas. Exp Oncol 41: 138-143, 2019. 
85. Reaven GM: Banting lecture 1988. Role of insulin resistance in human disease. Diabetes 37: 1595-1607, 1988.

86. Lee DY and Lee TS: Associations between metabolic syndrome and gynecologic cancer. Obstet Gynecol Sci 63: 215-224, 2020.

87. Esposito K, Capuano A and Giugliano D: Metabolic syndrome and cancer: Holistic or reductionist? Endocrine 45: 362-364, 2014.

88. Esposito K, Chiodini P, Colao A, Lenzi A and Giugliano D Metabolic syndrome and risk of cancer: A systematic review and meta-analysis. Diabetes Care 35: 2402-2411, 2012.

89. Trabert B, Wentzensen N, Felix AS, Yang HP, Sherman ME and Brinton LA: Metabolic syndrome and risk of endometrial cancer in the united states: A study in the SEER-medicare linked database. Cancer Epidemiol Biomarkers Prev 24: 261-267, 2015.

90. Jee SH, Kim HJ and Lee J: Obesity, insulin resistance and cancer risk. Yonsei Med J 46: 449-455, 2005.

91. van Kruijsdijk RC, van der Wall E and Visseren FL: Obesity and cancer: The role of dysfunctional adipose tissue. Cancer Epidemiol Biomarkers Prev 18: 2569-2578, 2009.

92.Iyengar NM, Hudis CA and Dannenberg AJ: Obesity and cancer: Local and systemic mechanisms. Annu Rev Med 66 297-309, 2015.

93. Yagen JD and Davidson NE: Estrogen carcinogenesis in breast cancer. N Engl J Med 354: 270-282, 2006.

94. André F, Rigot V, Remacle-Bonnet M, Luis J, Pommier G and Marvaldi J: Protein kinases C-gamma and -delta are involved in insulin-like growth factor I-induced migration of colonic epithelial cells. Gastroenterology 116: 64-77, 1999.

95. André F, Rigot V, Thimonier J, Montixi C, Parat F, Pommier G, Marvaldi $J$ and Luis J: Integrins and E-cadherin cooperate with IGF-I to induce migration of epithelial colonic cells. Int J Cancer 83: 497-505, 1999.

96. Akagi Y, Liu W, Zebrowski B, Xie K and Ellis LM: Regulation of vascular endothelial growth factor expression in human colon cancer by insulin-like growth factor-I. Cancer Res 58: 4008-4014, 1998.

97. Wu Y, Yakar S, Zhao L, Hemminghausen L and LeRoith D: Circulating insulin-like growth factor-I levels regulate colon cancer growth and metastasis. Cancer Res 62: 1030-1035, 2002

98. Fader AN, Arriba LN, Frasure HE and von Gruenigen VE: Endometrial cancer and obesity: Epidiomiology, biomarkers, prevention and survivorship. Gynecol Oncol 114: 121-127, 2009

99. Koczorowska MM, Kwasniewska A and Gozdzicka-Jozefiak A IGF1 mRNA isoform expression in the cervix of HPV-positive woman with pre-cancerous and cancerous lesions. Exp The Med 2: 149-156, 2011.

100. Philippou A, Armakolas A, Pantleakou Z, Pissimissis N, Nezos A Theos A, Kaparelou M, Armakolas N, Pneumaticos SG and Koutsilieris M: IGFF1Ec expression in MG-63 human osteoblast-like osteosarcoma cells. Anticancer Res 31: 4259-4265, 2011

101. McKoy G, Ashley W, Mander J, Yang SY, Williams N, Russell B and Goldspink G: Expression of insulin-like growth factor-1 splice variants and structural genes in rabbit skeletal muscle induced by stretch and stimulation. J Physiol 516: 583-592, 1999.

102. Hameed M, Orrell RW, Cobbold M, Goldspink G and Harridge SD: Expression of IGF-I splice variants in young and old human skeletal muscle after high resistance exercise. J Physiol 547: 247-254, 2003.

103. Hameed M, Lange KH, Andersen JL, Schjerling P, Kjaer M, Harrigde SD and Goldspink G: The effect of recombinan human growth hormone and resistance training of IGF-I mRNA expression in the muscles of elderly men. J Physiol 555: 231-240, 2004

104. Bickel CS, Slade J, Mahoney E, Haddad F, Dudley GA and Adams GR: Time course of molecular responses of human skeletal muscle to acute bouts or resistance exercise. J Appl Physiol (1985) 98: 482-488, 2005.

105. Kim JS, Cross JM and Bamman MM: Impact of resistance loading on myostatin expression and cell cycle regulation in young and older men and women. Am J Physiol Endocrinol Metab 288: E1110-E1119, 2005.

106. Philippou A, Papageorgiou E, Bogdanis G, Halapas A, Sourla A, Maridaki M, Pissimissis N and Koutsilieris M: Expression of IGF-1 isoforms after exercise-induced muscle damage in humans: Characterization of the MGF E peptide actions in vitro. In Vivo 23: 567-575, 2009.

107. Carpenter V, Matthews K, Devlin G, Stuart S, Jensen J, Conaglen J, Jeanplong F, Goldspink P, Yang SY, Goldspink G, et al: Mechano-growth factor reduces loss of cardiac function in acute myocardial infarction. Heart Lung Circ 17: 33-39, 2008.
108. Stavropoulou A, Halapas A, Sourla A, Philippou A, Papageorgiou E, Papalois A and Koutsilieris M: IGF-1 expression in infarcted myocardium and MGF E peptide actions in rat cardiomyocytes in vitro. Mol Med 15: 127-135, 2009.

109. Armakolas A, Philippou A, Panteleakou Z, Nezos A, Sourla A, Petraki C and Koutsilieris M: Preferential expression of IGF-IEc (MGF) transcript in cancerous tissues of human prostate: Evidence for a novel and autonomous growth factor activity of MGF E peptide in human prostate cancer cells. Prostate 70 1233-1242, 2010.

110. Liu JP, Baker J, Perkins AS, Robertson EJ and Efstratiadis A: Mice carrying null mutations of the genes encoding insulin-like growth factor I (Igf-1) and type 1 IGF receptor (Igf 1r). Cell 75: 59-72, 1993

111. Siddle K, Ursø B, Niesler CA, Cope DL, Molina L, Surinya KH and Soos MA: Specificity in ligand binding and intracellular signaling by insulin and insulin-like growth factor receptors. Biochem Soc Trans 29: 513-525, 2001.

112. Laviola L, Natalicchio A and Giorgiono F: The IGF-I signaling pathway. Curr Pharm Des 13: 663-669, 2007

113. Barton ER, Park S, James JK, Makarewich CA, Philippou A, Eletto D, Lei H, Brisson B, Ostrovsky O, Li Z and Argon Y: Deletion of muscle GRP94 impairs both muscle and body growth by inhibiting local IGF production. FASEB J 26 : 3691-3702, 2012.

114. Wu JW, Boudreau DM, Park Y, Simonds NI and Freedman AN: Commonly used diabetes and cardiovascular medications and cancer recurrence and cancer-specific mortality: A review of the literature. Expert Opin Drug Saf 13: 1071-1099, 2014.

115. Zhang ZJ and $\mathrm{Li} \mathrm{S}$ : The prognostic value of metformin for cancer patients with concurrent diabetes: A systematic review and meta-analysis. Diabetes Obes Metab 16: 707-710, 2014.

116. Bredholt G, Mannelqvist M, Stefansson IM, Birkeland E, B $\varnothing$ TH, Øyan AM, Trovik J, Kalland KH, Jonassen I, Salvesen HB, et al: Tumor necrosis is an important hallmark of aggressive endometrial cancer and associates with hypoxia, angiogenesis and inflammation responses. Oncotarget 6: 39676-39691, 2015.

117. Armakolas A, Kararelou M, Dimakakos A, Papageorgiou E, Armakolas N, Antonopoulos A, Petraki C, Lekarakou M, Lelovas P, Stathaki M, et al: Oncogenic role of the Ec peptide of the IGF-1Ec isoform in prostate cancer. Mol Med 21: 167-179, 2015.

118. Papageorgiou E, Philippou A, Armakolas A, Christopoulos PF, Dimakakos A and Koutsilieris M: The human Ec peptide: The active core of a progression growth factor with species-specific mode of action. Hormones (Athens) 15: 423-434, 2016

119. Karagiannis AK, Philippou A, Tseleni-Balafouta S, Zevolis E Nakouti T, Tsopanomichalou-Gklotsou M, Psarras V and Koutsilieris M: IGF-IEc expression is associeted with advanced differentied thyroid cancer. Anticancer Res 39: 2811-2819, 2019.

120. Irwin JC, de las Fuentes L, Dsupin BA and Giudice LC: Insulin-like growth factor regulation of human endometrial stromal cell function: Coordinate effects on insulin-like growth factor binding protein-1, cell proliferation and prolactin secretion. Regul Pept 48: 165-177, 1993.

121. Tang XM, Rossi MJ, Mastrerson BJ and Chegini N: Insulin-like growth factor I (IGF-I), IGF-I receptors, and IGF binding proteins 1-4 in human uterine tissue: Tissue localization and IGF-I action in endometrial stromal and myometrial smooth muscle cells in vitro. Biol Reprod 50: 1113-1125, 1994

122. Giudice LC, Dsupin BA, Jin IH, Vu TH and Hoffman AF: Differential expression of messenger ribonucleic acids encoding insulin-like growth factors and their receptors in human uterine endometrium and decidua. J Clin Endocrinol Metab 76: 1115-1122, 1993.

123. Zhou J, Dsupin BA, Giudice LC and Bondy CA: Insulin-like growth factor system gene expression in human endometrium during menstrual cycle. J Clin Endocrinol Metab 79: 1723-1734, 1994.

124. Laatikainen TJ, Toma EI and Voutilainen RJ: The expression of insulin-like growth factor and its binding protein RNA in the endometrium of postmenopausal patients with breast cancer receiving tamoxifen. Cancer 76: 1406-1410, 1995.

125. Elkas J, Gray K, Howard L, Petit N, Pohl J and Armstrong A: The effects of tamoxifen on endometrial insulin-like growth factor-1 expression. Obstet Gynecol 91: 45-50, 1998.

126. Mairano E, Loverro G, Viale G, Giannini T, Napoli A and Perlino E: Insulin-like growth factor-I expression in normal and diseased endometrium. Int J Cancer 80: 188-193, 1999.

127. O'Toole SA, Dunn E, Sheppard BL Sheils O, O'Leary JJ, Wuttke W and Seidlova-Wuttke D: Oestrogen regulated gene expression in normal and malignant endometrial tissue. Maturitas 51: 187-198, 2005. 
128. Bruchim I, Sarfstein R and Werner H: The IGF hormonal network in endometrial cancer: Functions, regulation, and targeting approaches. Front Endocrinol (Lausanne) 5: 76, 2014.

129. Soufla G, Sifakis S and Spandidos DA: FGF2 transcript levels are positively correlated with EGF and IGF-1 in the malignant endometrium. Cancer Lett 259: 146-155, 2008.

130. Pengchong $\mathrm{H}$ and Tao H: Expression of IGF-1R, VEGF-C and D2-40 and their correlation with lymph node metastasis in endometrial adenocarcinoma. Eur $\mathbf{J}$ Gynecol Oncol 32: 660-664, 2011.

131. Yi HK, Kim SY, Hwang PH, Kim CY, Yang DH, Oh Y and Lee DY: Impact of PTEN on the expression of insulin-like growth factors (IGFs) and IGF-binding proteins in human gastric adenocarcinoma cells. Biochem Biophys Res Commun 330: 760-767, 2005.

132. McCamplell AS, Broaddus RR, Loose DS and Davies PJ: Overexpression of the insulin-like growth factor I receptor and activation of the AKT pathway in hyperplastic endometrium. Clin Cancer Res 12: 6373-6378, 2006.

133. Dong L, Du M and Lv Q: Picropodophyllin inhibits type I endometrial cancer cell proliferation via disruption of the PI3K/Akt pathway. Acta Biochim Biophys Sin (Shanghai) 51: 753-760, 2019.

134. Leung PS, Aronson WJ, Ngo TH, Golding LA and Barnard RJ: Exercise alters the IGF axis in vivo and increases p53 protein in prostate tumor cells in vitro. J Appl Physiol (1985) 96: 450-454, 2004.

135. Tucci P: Caloric restriciton: Is mammalian life exptension linked to p53? Aging (Albany NY) 4: 525-534, 2012.

136. Luo X, Jiang X, Li J, Bai Y, Li Z, Wei P, Sun S, Liang Y, Han S $\mathrm{Li} \mathrm{X}$ and Zhang B: Insulin-like growth factor-1 attenuates oxidative stress-induced hepatocyte premature senescence in liver fibrogenesis via regulating nuclear p53-progerin interaction. Cell Death Dis 10: 451, 2019.

137. Tran D, Bergholz J, Zhang H, He H, Wang Y, Zhang Y, Li Q, Kirkland JL and Xiao ZX: Insulin-like growth factor-1 regulates the SIRT1-p53 pathway in cellular senescence. Aging Cell 13: 669-678, 2014.

138. Attias-Geva Z, Bentov I, Kidrom D, Amichay K, Sarfstein R, Fishman A, Bruchim I and Werner H: p53 regulates insulin-like growth factor-I receptor gene expression in uterine serous carcinoma and predicts responsiveness to an insulin-like growth factor-I receptor-directed targeted therapy. Eur J Cancer 48: 1570-1580, 2012.

139. Altieri DC: Survivin, cancer networks and pathway-directed drug discovery. Nat Rev Cancer 8: 61-70, 2008.
140. Takai N, Miyazaki T, Nishida M, Nasu K and Miyakawa I: Survivin expression correlates with clinical stage, histological grade, invasive behavior and survival rate in endometrial carcinoma. Cancer Lett 184: 105-116, 2002.

141. Tran J, Master Z, Yu JL, Rak J, Dumont DJ and Kerbel RS: A role for survivin in chemoresistance of endothelial cells mediated by VEGF. Proc Natl Acad Sci USA 99: 4349-4354, 2002.

142. Altieri DC: Survivin, versatile modulation of cell division and apoptosis in cancer. Oncogene 22: 8581-8589, 2003.

143. Altieri DC: Survivin and apoptosis control. Adv Cancer Res 88 $31-35,2003$

144. Mita AC, Mita MM, Nawrocki ST and Giles FJ: Survivin: Key regular of mitosis and apoptosis and novel target for cancer therapeutics. Clin Cancer Res 14: 5000-5005, 2008.

145. Liu X, Chen H, Hou Y, Ma X, Ye M, Huang R, Hu B, Cao H, $\mathrm{Xu} \mathrm{L}$, Liu M, et al: Adaptive EGF expression sensitizes pancreatic cancer cells to ionizing radiation through activation of the cyclin D1/P53/PARP pathway. Int J Oncol 54: 1466-1480, 2019.

146. Vaira V, Lee CW, Goel HL, Bosari S, Languino LR and Altieri DC: Regulation of surivivn expression by IGF-I/mTOR signaling. Oncogene 26: 2678-2684, 2007.

147. Song K, Shankar E, Yang J, Bane KL, Wahdan-Alaswad R and Danielpour D: Critical role of a survivin/TGF- $\beta / \mathrm{mTORC} 1$ axis in IGF-I-mediated growth of prostate epithelial cells. PLoS One 8: e61896, 2013.

148. Sato A, Oya M, Ito K, Mizuno R, Horiguchi Y, Umezawa K, Hayakawa M and Murai M: Survivin associates with cell proliferation in renal cancer cells: Regulation of survivin expression by insulin-like growth factor-1, interferon-gamma and a novel NK-kappaB inhibitor. Int J Oncol 28: 841-846, 2006.

149. Oh SH, Jin Q, Kim ES, Khuri FR and Lee HY: Insulin-like growth factor-I receptor signaling pathway induces resistance to the apoptotic activitis of SCH66336 (lonafarnib) through Akt/mammalian target of rapamycin-mediated increases in survivin expression. Clin Cancer Res 14: 1581-1589, 2008.

150. Morgillo F, Woo JK, Kim ES, Hong WK and Lee HY: Heterodimerization of insulin-like growth factor receptor/epidermal growth factor receptor and induction of survivin expression counteract the antitumor action of erlotinid. Cancer Res 66: 10100-10111, 2006.

This work is licensed under a Creative Commons Attribution-NonCommercial-NoDerivatives 4.0 International (CC BY-NC-ND 4.0) License. 